\title{
WEIR
}

SOME DEVELOPMENTS

IN

AIRCRAFT DESIGN

1919 



\section{Some Developments}

In Aircraft Design and Application During the War

By The Right Honourable IORD WEIR OF EASTWOOD, P.C., Honorary FELlow.

Read before The North East Coast Institution of Engineers and Shipbuilders roth Fuly, 1919. Reprinted by order of the Council. 



\section{Some Developments In Aircraft Design and Application During the War}

By The Right Honourable I.ORD WEIR OF EASTWOOD, P.C., HONORARY FELLOW.

Read before The North East Coast Institution of Engineers and Shipbuilders roth Fuly, I919. Reprinted by order of the Council. 


\section{ERRATA.}

Page 53. Table, Particulars Napier "Lion" Engine:--

1. Max. B. H.P., should be... ... ... 500

2. Normal propeller speed, should be ... 1,318

3. Dry weight in lbs., should be $\ldots \quad \ldots \quad 840$ 


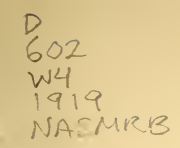

SOME DEVELOPMENTS IN AIRCRAFT DFSIGN AND APPLICATION DURING THE WAR.

By The Right Honourable LORD Weir of Eastwood, P.C, Honorary Fethow. 


\title{
SOME DEVELOPMENTS IN AIRCRAFT DESIGN AND APPLICATION DURING THE WAR.
}

\author{
By The Right Honourable LORD Weir of EastwoOd, P.C., \\ Honorary Fellow.
}
[Read at the Victory Meeting in Newcastle-on-Tyne on the 10тн JuLy, 1919.]

Any attempt to review the progress or development of aviation during the war, and to confine such a review to the permissible limits of a Paper, involves a mere indication of some of the more salient features of the development. Moreover, it is difficult to confine any such review entirely to the scientific or engineering aspect of the problem, on account of the peculiarly close association of the technique of construction with the technique of use. The war development of a technical product, such as an aeroplane, necessarily comprises the rapid embodiment of field experience in the design and production of matériel, and this compelling influence during the war largely governed the policy of design, supply and production.

In August, 1914, the British Air Services consisted of a Naval wing and a Military wing, the first controlled by the Admiralty, and the second by the War Office. The Naval wing, or Royal Naval Air Service as it was termed, possessed a total of 9:3 machines, the Military wing or Royal Flying Corps possessed a total of 179 machines. In October, 1918, just prior to the Armistice, the Royal Air Force possessed over 22,000 effective machines.

For the first two years of the war, the supply organizations for aircraft were Departments of the War Office and Admiralty, and no distinct technical departments existed. In January, 1917, the second Air Board, under the Chairmanship of Viscount 
Cowdray succeeded the original Air Board under Viscount Curzon, and was constituted with additional duties and responsibilities. The Board became responsible for the allocation of aeronautical supplies between the two Flying Services, and for the supervision of design of all aeronautical material, this latter responsibility being vested in the technical department of the Air Board under Brig.-General Pitcher. Concurrently with this, the entire responsibility for supply and production of all aircraft matériel was handed over by the War Office and Admiralty to the Ministry of Munitions. Towards the end of 1917, a movement in favour of concentrating the entire administration of everything relating to war aviation in a single Government department crystallized in the constitution of the Air Ministry under a Secretary of State for Air, the Naval and Military Air Services being amalgamated to form the Royal Air Force in April, 1918.

The establishment of the Royal Air Force as an independent fighting force of the Crown has been thoroughly well justified, and the progress with regard to civil aviation in this country since the Armistice is largely due to the existence of a single Air Authority. Concurrently with the institution of the Air Ministry, the necessity of placing design and supply under a single authority was recognized by the constitution, within the Ministry of Munitions, of the Aircraft Production Department, which assumed full responsibility for all questions of design, supply and production.

An appreciation of the progress made in the domain of supply and production can be obtained from the fact that the average monthly delivery of aeroplanes either from British or foreign sources to our flying service during the first twelve months of the war was 50 per month, while, during the last twelve months of the war, the average deliveries were 2,700 per month. The capacity of the facilities in this country for the production of aeroplanes at the date of the Armistice was approximately 3,500 complete machines per month. To those associated with marine engineering, it may be of interest to state that the total horse-power of aero engines produced in the last twelve months of the war, approximated to 8 millions of brake horse-power, a figure quit'e comparable with the total horse-power of the marine engine output of the country.

It may be of interest to recite some of the difficulties encountered in this work, although perhaps the more important of these difficulties were inseparable from the industrial position 
of the country at the period when the effort towards expansion was made:-

1.-The lack of highly skilled labour, in particular that required for engine production, due to the almost complete absorption of such labour by other and earlier war enterprises.

2.--The very high standard of material and workmanship involved so that safety might be ensured on the low permissible weight of the product.

3.--The necessity of creating and building up entirely new manufacturing facilities and organizations.

4.-The grave influence on production of modifications in design shown necessary by field experience, and the necessity for the rapid embodiment of these in the product.

5.-The inability to take the fullest advantages of standardization, owing to the necessity of making continuous progress in design and performances of machines.

6.-The extreme complexity and variety of the elements contributing to the provision and equipment of war aeroplanes.

For example, the provision of satisfactory timber was a continual difficulty - at times an actual menace to the whole development. The textile problem became very grave when the supplies of Russian flax were cut off, and we were compelled to develop additional sources in Ireland and in the Colonies. Acute difficulties were experienced in connexion with the development of the chemicals required for dope manufacture. At other times, the supply of machine guns gave much anxiety, while the development of the synchronizing gear for these guns necessitated very urgent treatment.

The production of ball bearings involved the provision of new facilities on a colossal scale. The magneto supply involved the building up of an entirely new industry, while the manufacture of the numerous classes of instruments, cameras, radiators and other fittings in each case formed a problem by itself.

The solution of these problems from a production point of view constitutes an outstanding example of the enterprise, courage and ingenuity of British industry. Many mistakes were made, but most of the difficulties were solved and many

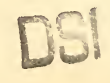


valuable lessons have been learned. It is a matter of great regret that so many of these enterprises, built up for specific war requirements, cannot be maintained under peace conditions. The development of civil aviation will not, for many years, absorb even a fraction of the war facilities, and a large amount of waste cannot be avoided in the reduction of these industries to a peace-time basis.

The constitution in 1917 of the first Technical Department dealing with aircraft design represented one of the most valuable steps in advance of previous organization, and the work of this department very largely contributed to the position of technical supremacy held by this country at the close of the war. One of the factors contributing to this success was undoubtedly the adoption of a policy of giving ample freedom of opportunity to private designers, because in the development of a new art, such as aircraft design, any adherence to a single school of thought is dangerous, and the basis of design and experiment should be broadened as much as possible.

In the earlier days of the development the official Government designs of the Royal Aircraft Factory at Farnborough predominated, but the change in policy should not be taken to represent a reflection on the many valuable designs produced at Farnborough. These designs exercised a great influence on all future designs, while the meticulous care in the details, which was the feature of Farnborough practice, has been wholly useful and valuable in its general influence. To the British aircraft designers as a whole, and in particular to the pioneer designers and manufacturers, the greatest credit is due for their courage, skill and ingenuity.

Such is the briefest possible review of the political and administrative conditions under which the developments in war aviation have been carried out. In dealing with the salient features of progress and design two aspects have been separately treated-the aerodynamic aspect and the applicational aspect. As regards seaplanes it is not proposed to deal with their detail development, as this followed generally on the same lines as the aeronlanes with the special adaptations to meet marine conditions.

\section{Part I.-Aeromynamical Aspect.}

Loading.- The outstanding feature desired in war aeroplane performance was expressed generally as the maximum of speed and climb, and it was soon perceived that this feature could 
be best achieved by a reduction of the weight carried per horsepower. The advance in other aerodynamic features such as wing section, reduction of air resistance, etc., was considerable, but could not be compared in importance with the reduction of the weight per horse-power.

At the beginning of the war, loadings were about $23 \mathrm{lbs}$. per horse-power and $4 \mathrm{lbs}$. per square foot of lifting surface; at the close of the war, nearly $7 \mathrm{lbs}$. per horse-power, and $10 \mathrm{lbs}$. per square foot. This is a remarkable result when it is considered that $7 \mathrm{lbs}$. per horse-power represents the power loading of the total weight of the aeroplane, comprising the engine, its petrol and oil, the aeroplane itself, the pilot and all his fighting equipment. The rate of progress achieved in this development

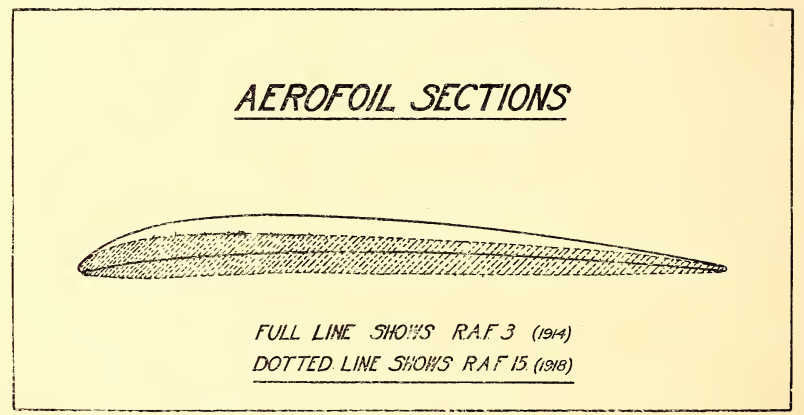

Fig 1 .

entailed a correspondingly large demand on the skill of the pilot, but it was found that the pilot's skill always advanced as rapidly as the demands upon it.

Wing Sections.-Wing sections steadily developed from the early sections with their hollow undersides and tops of almost circular camber, to the high efficiency sections of the present day with flat undersides bulged slightly downwards for the spars, and upper surfaces with a quick nose curvature, flattened top and easy run aft.

The illustration, Fig. 1, shows these differences fairly well. It may be noted as an interesting fact, that the Germans at no time made use of a high efficiency section such as the R.A.F. 15 shown.

Air Resistance.-No revolutionary advances have been made during the war in regard to the reduction of air resistance, but 
the general trend has been the more rigid application of previous Inowledge; the conversion of piano wire or cable to streamline wires for main bracing is perhaps the most noteworthy feature. Until quite recently stream!ine wires were not adopted by any other country than this, although for fast aeroplanes the gain is considerable -approaching ten miles an hour on a machine with a speed of 110 m.p.h.

The fuselages were made of fairer shape, and pilots and accessories were more carefully enclosed and protected.

Stresses and Factors of Safety.-At the outbreak of hostilities very little was known of the magnitude of the forces which might occur in flight, and certain more or less arbitrary rules were used in determining the strength of the aeroplane. Many possible methods of failure were never considered, and in some cases it was only through the light shed by certain accidents that progress was made. Certain definite forms of failure which are now always considered and guarded against were only discovered after long and careful examination and analysis of accidents.

When an aeroplane is flying level at a constant speed, the air loads acting vertically on the lifting surfaces (wings and tail) must of course be equal to the total weight of the aeroplane. Other conditions must be simultaneously fulfilled, but this is the primary one.

This air load on the wings is known as the normal or unit flight load and is the basis of all strength calculations. It will be clear that in order to accelerate the aeroplane, extra forces must be applied to it, and so in many manœuvres through which the aeroplane is put, extra loads are thrown upon the structure.

These forces are measured in terms of the unit flight load, and their magnitudes are determined either by calculation or by experiment. Both methods are used, and the advance in knowledge on this question, during the war, has been one of the principal causes of the elimination of practically all accidents which may be genuinely attributed to structural failure, and the great reduction in the percentage weight of aeroplane structures. The experimental method of determining the values of these loads consisted in carrying an accelerometer on an aeroplane. This instrument was self-recording and registered the amount of the accelerations given to the craft during various manœuvres. Developed by Professor Lindemann and Dr. Searle at the R.A.I'. its valu : has been considerable. The illustrations (Figs. 2 and 3) were obtained from one of their autographic records, and these and the attached table will give some idea of the value of the 
loads which occur during aerial manœuvres. It must be understood that these loads are not the maxima which could occur, but only the maxima registered during the experiments.
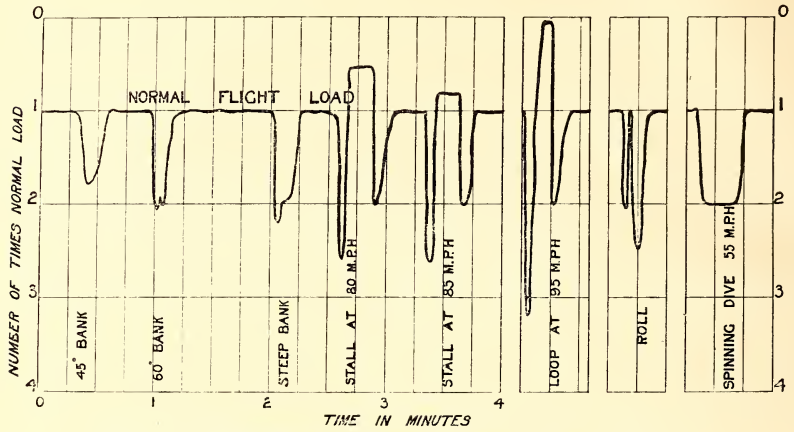

Fig. 2 -Accelerometer Tests. Flight Loads. B.E. 2C.
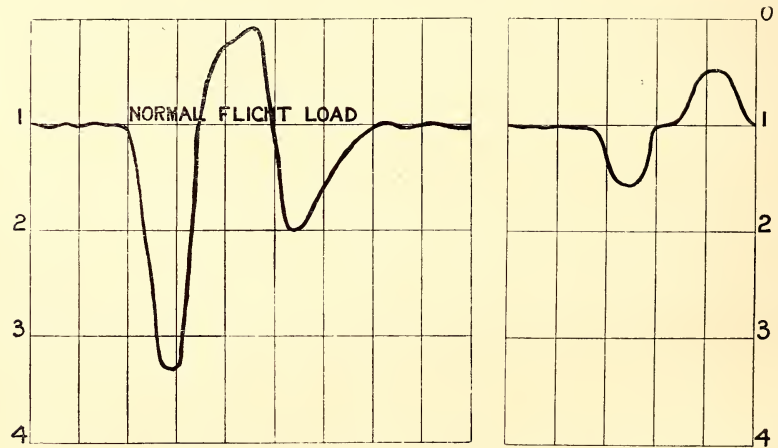

Fig. 3.-Accelerometer Tests. Loads on B.E. 2C.

Table of Loads.

Ordinary bumpy weather. Spiral dive at $70 \mathrm{~m} . \mathrm{p} . \mathrm{h}$. In a mock fight between S.E.5A, and R.E.8
$1 \frac{1}{2}$ to $\frac{1}{2}$ normal load. $2 \cdot 8$ times normal load.

3 times normal load was common; at times this increased to nearly 4.

Until all the loads which can possibly occur on an aeroplane are known it is impossible to design an absolutely scientific structure, but considerable progress has been made during the war in this direction, and it is at least possible now to design 
a structure that will not break in the air except under certain conditions against which the pilot can be warned.

In all other branches of engineering the prevention of failure is obtained by the introduction of a factor of safety, so that the highest possible loading which can occur in the structure stresses the material to only a fraction of its ultimate stress.

With an aeroplane this method is impossible on account of weight limitations, and in consequence a method is adopted of specifying load factors instead of factors of safety.

This method consists of determining-largely as a result of previous experience-what extra loads any particular type of aeroplane is likely to meet under the conditions of flight for which it is intended, and the structure is designed with just sufficient strength to carry these loads, that is to say, when these loads occur the material is stressed either up to its elastic or its ultimate stress. In the usual engineering sense, therefore, the factor of safety under this condition of flight is only one, while the load factor may be from four to seven, i.e., the loads which cause failure are from four to seven times normal flight loads as specified previously.

In aeroplanes of the scout class it has, been customary to ask for a load factor of seven, but this only corresponds to a factor of safety of about $0 \cdot 6$. That is to say, the aeroplane by certain manœuvres could be broken in the air. This fact is well known to all pilots and such a breakage now seldom occurs. It will be seen from the above table that in ordinary bumpy weather the loads were only increased about $1 \frac{1}{2}$ times normal.

Since all other increased loads arise from "stunts" it would appear that commercial aeroplanes will seldom have to contend with the heavy loads met with in war flying, and it may be possible on this account to cut down load factors especially on heavier types. The illustration shows the difference between the loads in a loop and loads due to gusty weather upon the same aeroplane.

Analysis of Weights.-As in all forms of science, progress is very largely dependent on the ability to measure accurately the various items and factors. No genius can make up for the neglect of this essential. Once all the factors, whether they be weights, sizes or performances, are accurately measured, it is not so difficult to decide in which direction to proceed. A large amount of attention was given to the careful analysis of the weights of all available aeroplanes, good or bad, and tables were prepared of which samples are given in Figs. 4, 5 and 6. 


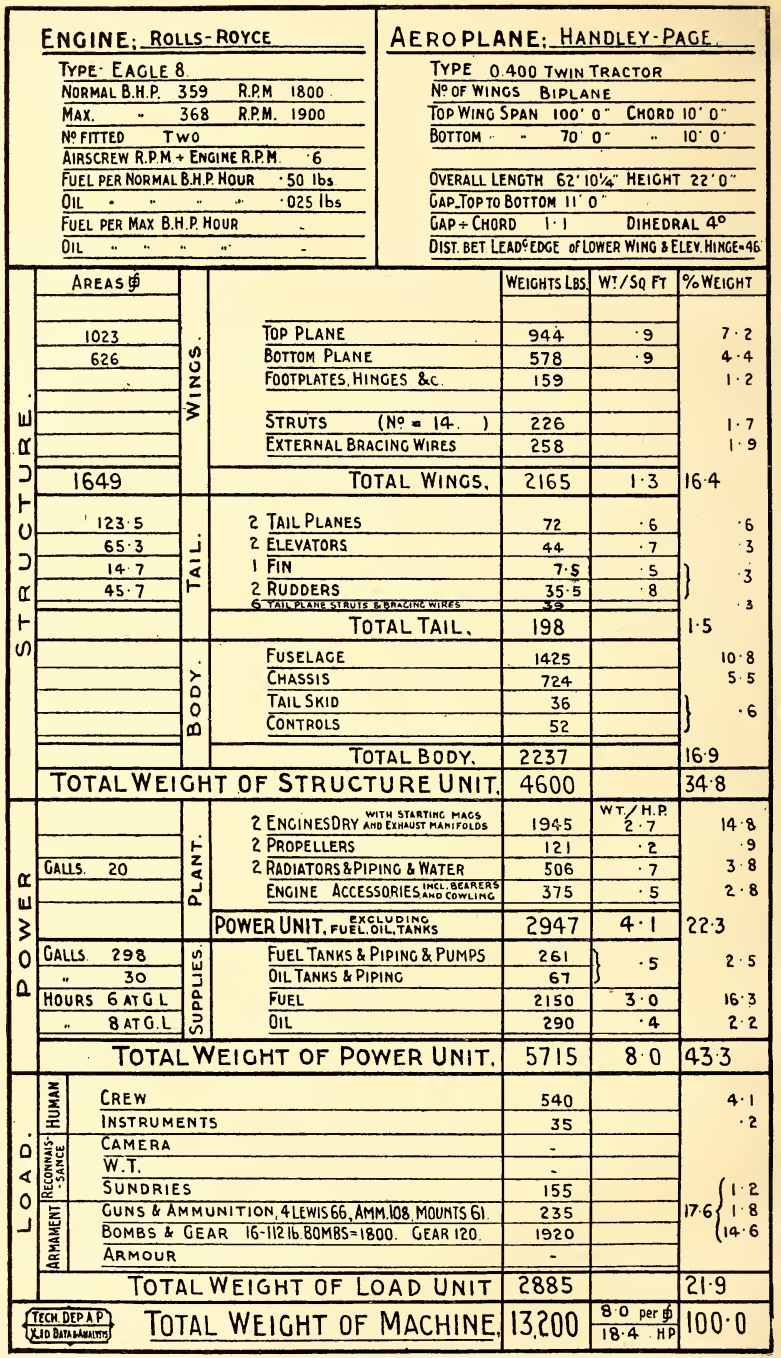

Fig. 4.-Analysis of Weight. De Havilland 4. 


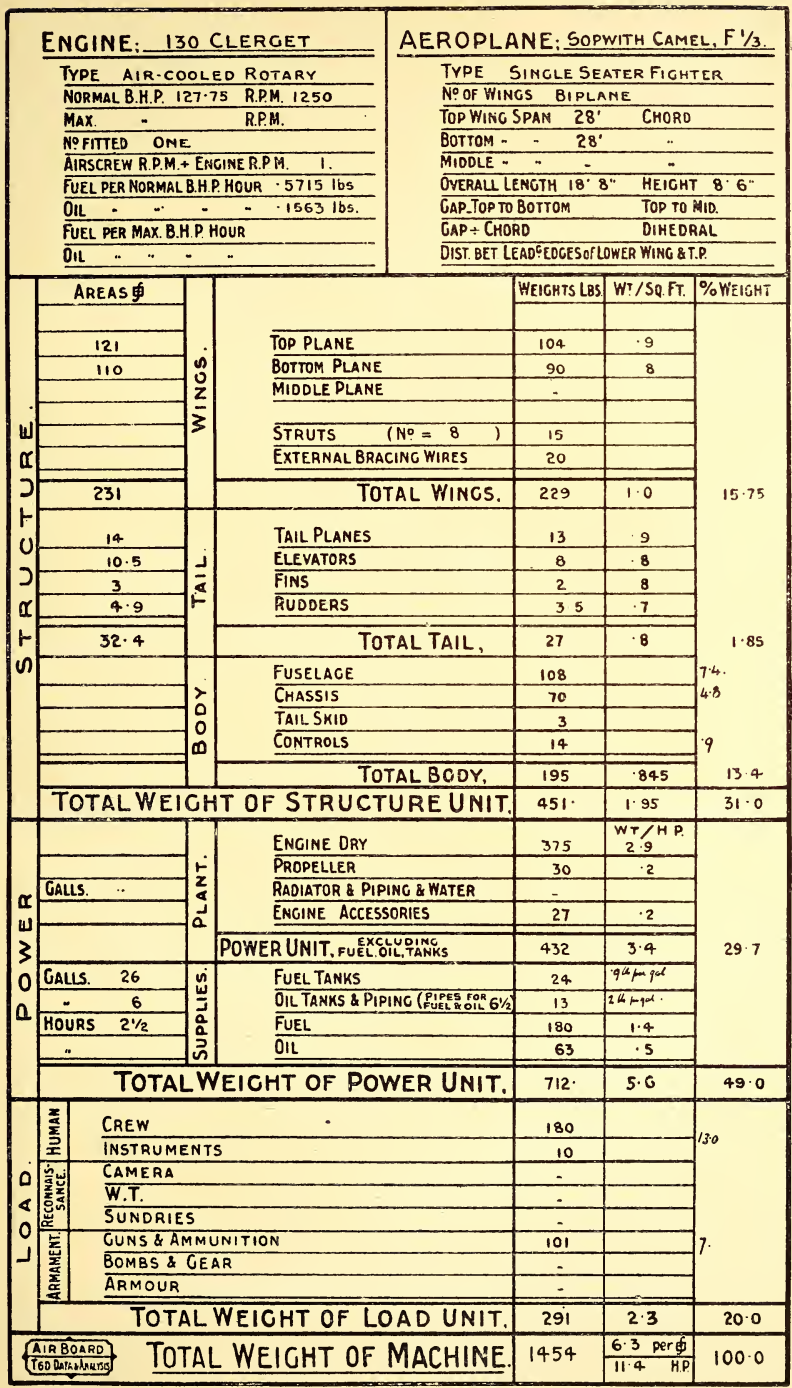

Fig, 5.-Analysis of Weight. Sopwith Camet. 
ENGINE: 250 ROLLS-ROYCE MK. III. TYPE WATER COOLED V $60^{\circ}$ NORMAL B H.P 270 R.P.M 160 \begin{tabular}{lll}
\hline MAX & 286 & RPM. 1850 \\
\hline
\end{tabular} NOFITTED ONE

AIRSCREW R PM + ENGINE R.P.M. $\cdot 64$ FUEL PER NORMAL B.HP. HOUR $.5706 \mathrm{lbS}$ \begin{tabular}{llllll}
\hline OIL & " & . &. & 0254 Ibs. \\
\hline
\end{tabular} FUEL PER MAX B.H P HOUR $-$

\section{AERO PLANE: DE HAVILLAMD 4. \\ TYPE TWO SEATER TRACTOR NOOF WINGS BIPLANE TOPWINO SPAN 4.2.6" CHORD BOTTOM - " $42^{\prime} 6^{\prime \prime}$ " PHOOE- - - OVERALL LENGTH $30^{\circ} 8^{\prime \prime}$ HEIGHT $10^{\prime} 5^{\prime \prime}$ GAP + CHORD DIHEDRAL DIST. BET.LEADCEDGES OF LOWER HING \&T.P.}

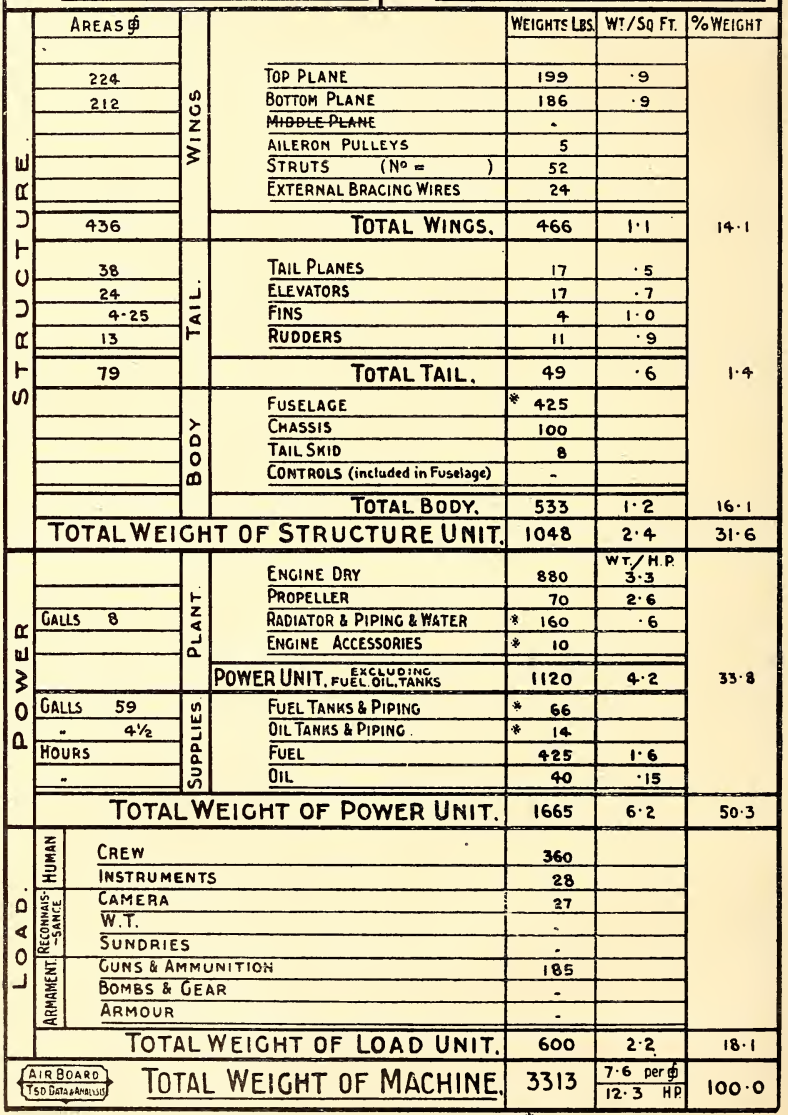

\footnotetext{
tapproximate
}

Fig. 6.-Analysis of Whight. Handley Pagi 0/400. 
By a study and comparison of these results in conjunction with the strength of the various aeroplanes, much knowledge of the possibilities of construction was obtained. The interesting fact was arrived at-that for a range of well designed practical war types, the structural percentage remains roughly constant for aeroplanes of total weight varying from 1,000 to $30,000 \mathrm{lbs}$.

From a theoretical point of view, this is somewhat surprising because, as is well known to engineers, the law of dimensions lays down that area increases as the square and weight as the cube of the dimensions, and that this will therefore put a limit on size. In fact, a very eminent aerodynamic theorist, working on these lines several years ago, put the limit of the weight of an aeroplane at about 10,000 lbs. There is very little doubt now that aeroplanes of $100,000 \mathrm{lbs}$. are a practical proposition.

Some of the reasons for this apparent theoretical discrepancy may be of interest. One is, that the larger the aeroplane, the more sober is the method of progression. No one wants to loop or do vertical banks on a big passenger aeroplane, and therefore it is not necessary to maintain as ligh a strength factor on the big type as on the small. As far as actual flying stresses are concerned, it would be possible for an aeroplane with a load factor of only $1 \frac{1}{2}$ to be flown without collapse even on a windy day. This statement is only used for illustration, and must not be taken to suggest that a load factor of $1 \frac{1}{2}$ would produce a practical aeroplane; it would probably be too weak to stand landing. Another reason for the discrepancy is, that the bigger the aeroplane the more detailed can be the design work, and it becomes possible to use material in a more efficient way.

It is not considered probable that aeroplanes made of wood will increase to a size representing a weight of much more than 40,000 lbs., but by the use of high grade steel and duralumin, it will certainly be possible to go far beyond this limit.

Influence of Tunnel Experiments.-At one time the small scale work carried out in the wind tunnel was regarded as of little practical value; now, judging by the results, I do not think that it would be too much to say that the work which was put into tunnel research, when this work at the National Physical Laboratory was under the direction of Mr. Leonard Bairstow, before as well as during the war, was the real basis of the technical success which we undoubtedly attained, particularly in the aerodynamic field. The data from such work is more useful to the designer from a comparative aspect than for the absolute values obtained, but without their help it is only too 
easy to stray oft into blind alleys leading nowhere except to disappointment.

Some designers have undoubtedly a wonderful facility in guessing the next step to take, but they are too few and far between for responsible authorities to rely solely upon them. In any case such men always work best if there is a solid background of research knowledge behind them, from which they draw sometimes perhaps unconsciously. In 1914 no private firns had a wind tunnel of their own or went in seriously for research. Now there are four or five first class installations in constant use by the desiguers of the manufacturing firms. As instance of more important results there now exists fairly exact knowledge of the best wing sections, strut shapes, propeller blades and body resistances.

Stability and Controllability.--There are two means of obtaining stability in an aeroplane; first, by means of an automatic device, such as a gyroscope, and second, by such a disposition of the surfaces of the aeroplane that the machine has inherent stability. Very little success has been obtained from the first method, but the second is now very largely employed.

Questions relating to stability and controllability are int1mately connected, but in one sense they are distinct. Thus it is possible to have an unstable aeroplane which is readily controllable and very popular with pilots.

Stability may be considered under three heads:-

Longitudinal stability ;

Lateral stability, and

Directional stability.

The first, longitudinal stability, is obtained by means of the tail plane, and the size of this for any particular type determines within limits the degree of stability. The fundamental point, however, is the position of the centre of gravity of the aeroplane relative to the main planes. If this is too far aft no tail plane can be found to give stability. The farther forward the centre of gravity, the smaller is the tail plane required.

The problems of lateral and directional stability are very closely connected, and must be considered together. Lateral stability is obtained by giving the main planes a dihedral angle, and directional stability is obtained by a proper regard to the dimensions and dispositions of the fins and rudders. The area of the fin and rudder required is a function of the dihedral angle.

The outbreak of war found us in a very favourable position 
with regard to the development of an inherently stable aesopiaue. 'ilhe importance of this feature from a military point of view had been fully realized, and special efiorts had been made to produce a stable and at the same time controllable aeroplane. I'hat these eftorts were successful was largely due to the late E. 'I'. Busk, of the Royal Aircratt Factory, as it was then called, and the B.E. 2c aeroplane, which embodied the results of his work, had been fully tested and demonstrated to possess complete inherent stability prior to the outbreak of war. Unfortunately, Mr. Busk was killed in a flying accident shortly after his experiments had been brought to a successful issue. However, his full scale research had been carried so far that the principles underlying the design of this machine could be applied to any other design of aeroplane. Subsequently nearly all machines were designed for inherent stability, except such types as were considered to be more suitable for their specific work if a certain degree of stability were sacrificed for very quick manœuvrability. An impression was prevalent, at any rate during the first two or three years of the war, that a stable aeroplane must necessarily be very heavy on its controls, and since quick manœurrability was an essential for fighting scouts, the aim of designers, encouraged by fighting pilots, was to obtain the maximum controllability and quickness of handling, irrespective of stability.

It was gradually realized that this was a mistaken view, and that the comparatively poor manœuvrability of some of the earlier stable machines was due, not to the fact of these machines being stable, but to the particular design of the controlling surfaces. A very great amount of research into the conditions governing stability and controllability was carried out both from the theoretical and experimental standpoint, and this revealed enough data to enable aeroplanes to be designed combining inherent stability with good manœuvrability, and as a result, the prejudice against stability in small fighting aeroplanes quickly disappeared.

A good example of the advantage of this is afforded by Captain Ball's wonderful return to our lines on his stable S.E. 5 machine after his controls had been almost completely shot away. The aeroplane practically flew itself back, and with only half of his normal elevator control he was able to make a safe landing on the aerodrome. Such a feat would have been out of the question on an unstable machine.

At the end of the war we were calling for aeroplanes with 
neutral stability for fighting work, i.e., aeroplanes which followed the pilot's mind and hand in whatever attitude they were put. For bombing and long distance work stability is a very important asset, as it relieves the pilot of fatigue, and facilitates the maintenance of his course and his sighting for bomb dropping. The disadvantages of not putting a sufficient amount of study into these features are demonstrated by German practice. Although a few of their small aeroplanes were fairly manœuvrable, their larger ones did not compare favourably with our own when tested under the same conditions, and in the case of their very large bombing aeroplanes we had evidence that the pilot's difficulties on a long flight were very considerable, and it is probably not too much to say that the heavy proportion of German bombers which were crashed on returning from their raids was largely due to lack of stability and controllability.

Monoplane, Biplane or Triplane.--During the war all these types have been experimented with, and in fact have been built on a production scale, and it cannot be definitely stated that one type is more suitable than another without knowing the exact purpose for which the aeroplane is required.

Broadly, the comparative advantages of the three types are as follows: In comparison with the biplane, the monoplane is 5 per cent. more efficient as a weight carrier per square foot, and can be made to afford a better fighting view. On the other hand, it is weaker for the same weight of structure, and is less manœuvrable for equal total weight. Similarly the triplane, comparing it to the biplane, is 5 per cent. less efficient, but is more manœuvrable, and affords opportunities for a deeper and therefore stronger main girder which gives it an advantage for the larger sizes. Incidentally, it is also more difficult and expensive to produce. The balance between advantage and disadvantage therefore depends upon the particular function required from an aeroplane, and also on the skill of the designer in overcoming the peculiar difficulties of his problem. But the general conclusion is that the monoplane is most suited for the very small aeroplane; the biplane for all general sizes, and probably the triplane for the very large sizes. Experience during the war in general bears this out, although there have been instances which might be taken as contradictory to this statement.

The importance of the successful use the Germans made of their Fokker monoplane should not be exaggerated, as the real reason for this success was the production in large numbers of a 
good single-seater with a rotary engine copied from the French Gnome, combined with the new synchronized guns, and a fresh method of attack. When we tested the aeroplane ourselves, and compared it with our own under simplar conditions, its performance was in fact very little superior to the B.E. 2c against which it was so effective.

Our designers, on the other hand, made a very successful triplane fighter with a similar sort of engine. The main objectives of the designer in this case were handiness and view ahead. Handiness was obtained by very small span, and view by placing the pilot so that his eye was in the line of the centre plane. However, as far as this country was concerned, the general decision was the selection of the biplane as the simplest and soundest type for all ordinary work.

Climb Requirements. - The most valuable quality in a war aeroplane and the one most difficult to supply is no doubt climb. Practically all other considerations are opposed to fast climb, such as high superficial loading, direct drive engines, high speed and long range. But the demand by pilots for a high rate of climb, both as a protection agaiust anti-aircraft fire and to increase their fighting capacity was so great, that this quality had to be provided. The range of guns, or rather their power of accurate shooting at a height, increased in an astonishing degree during the war. In the early days, a height of 3,000 feet was reasonably safe, and aeroplanes could do their work at that height. Then it was increased to $6,000,10,000$ and 15,000 feet. By the end of the war shooting even at 20,000 feet was unpleasantly accurate. Whenever a new type of aeroplane appeared which could operate at an increased height, it was immune for a period, and could do its work almost unmolested, and in some cases without being perceived; but this period seldom lasted long, and sometimes even before the new type was appearing in sufficiently large numbers to count seriously, it was outranged.

The same state of affairs applied to the height at which fighting took place, which gradually increased from year to year up to 20,000 feet. In order that the pilot could fight in a satisfactory manner he required a good rate of climb as well as the uppermost position. The difficulty of providing climb in an aeroplane during the first two years of the war was enhanced by the constant increase in the number of accessories required to enable the extra military functions to be carried out. These accessories added largely to the weight and also to the air 
resistance, and it was not until specially designed aeroplanes appeared that the position became satisfactory.

Interaction of Engine and Aeroplane Design.-Progress in aeroplane was very much bound up with the progress in engine design; in fact it can be broadly stated that during the whole of the war the aeroplane designers were waiting upon the engine designers, and as soon as any new engine was developed to a satisfactory point, it was but a short time before aeroplanes were in service, making the maximum use of such an engine, or at any rate a thoroughly effective use.

It is interesting to compare German practice with our own. The Germans realized at an early stage the necessity of large engines, and they concentrated their attention on the production of a first class but simple type of motor. This had a straight row of six cylinders of an average weight per horse-power, neither excessively heavy nor particularly light. They standardized this type at a comparatively early date and consequently made early advances in production and reliability.

Our policy was by no means so definite and our engine designers worked on a number of different types; air-cooled rotary, radial, and in $\mathrm{V}$, water cooled, 8 cylinder, 12 cylinders in $\mathrm{V}$ and 6 cylinders in line. At no time did we rigidly standardize a single type. In consequence, we had far bigger difficulties in production and on the whole our motors were not so reliable. Ultimately, however, we progressed much further than the Germans, both in the power of the engine, and in the reduction of weight per horse-power.

The reduction of weight of the aeroplane per horsepower can be obtained in either of two ways-(1) by having a very powerful engine of average weight per horse-power, so powerful that the weight of the pilot and his military gear is relatively an unimportant factor; or (2) by having an engine of very light weight per horse-power. This point is best illustrated by a short analysis in weight per horse-power, comparing two aeroplanes which are both single seated fighters, and of the same lbs. per horse-power.

Large Aeroplane.

300 H.P. Engine Weight

2 hours Fuel, Oil and Tanks

Pilot and Gear

Aeroplane Structure Weight

Total Weight, 2,700 lbs.
Small Aeroplane.

200 H.P. Engine Weight

Fuel, Oil and Tanks

Pilot and Gear

Aeroplane Structure Weight

3

9

Total Weight, 1,800 lbs. 
The first type has a large water cooled engine, is economical in fuel, and by reason of the size of the engine, the pilot and his gear account for only a small proportion of the total weight; whereas on the small aeroplane the engine is a light weight air cooled engine of heavier consumption, and the weight of pilot, etc., is a much larger proportion of the whole weight.

The two aeroplanes would practically give the same performance, but the smaller probably would be the better fighter

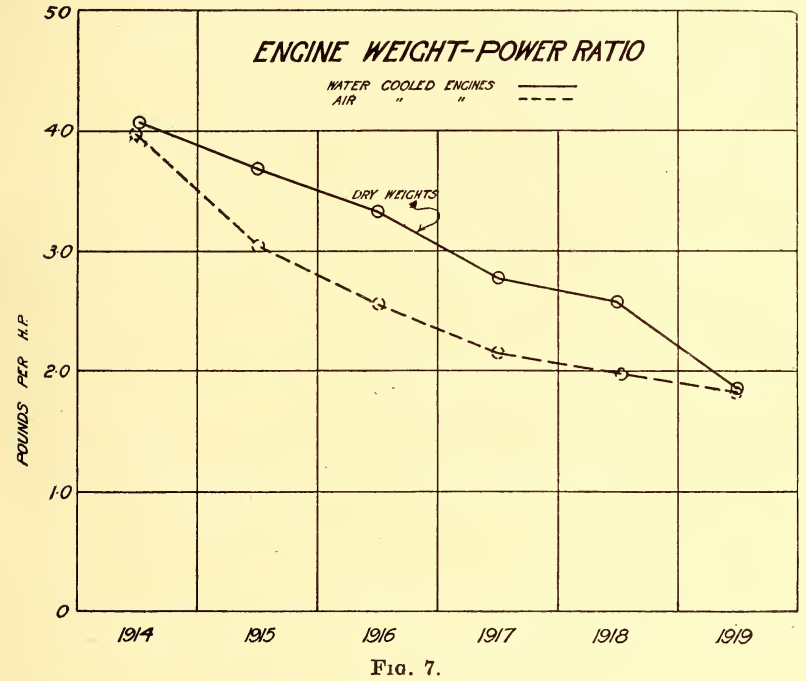

because of its greater manœuvrability. There are many other factors to take into account, such as reliability, pilot's view, ease of manufacture, etc., all of which must be considered before coming to a decision as to which is the better type.

Generally speaking the tendency during the war was towards the heavier aeroplane, although there were two periods when the light-weight engine reversed this. One was when the 80 Le Rhone Sopwith Pup supplanted the 140 R.A.F. B.E. 12, and th? two 100 horse-power pushers D.H. 2 and F. E. 8 ; the other was when the small air-cooled Wasp engine was competing with the 275 water-cooled Rolls Royce Falcon. 


\section{Part II.-Construction and Application.}

Wing Structure.-General development in wing construction of aeroplanes, during the war, has been more in the nature of refinement of detail, than of evolution of methods.

With increased knowledge concerning the loads to which the structure is subjected during flight, has come the possibility of more scientific proportioning of the structural members; but beyond this the general arrangement of the wing has remained unchanged. The structure percentage weight has shown the effect of increased knowledge, and this percentage has now reached a very low value.

The effect of attention to detail has also been to give a general cleaning up and simplicity to the appearance.

In external bracing, changes have taken place in some particulars. In 1914 the duplication of the main lift wires was considered to be very important, if not essential; now, in the event of one wire getting shot away, the loads are taken through the incidence wires, which are those seen when looking at a wing from the side. At the commencement of the war, hard drawn piano wire was used for the main lift and antiflying wires in many types; when this was not used, stranded cable was employed. The use of these materials has been superseded by streamline wires. These consist of high tensile steel rods of a lenticular section rolled from bar. The ends are left circular, and threaded to form a simple means of attachment to the fittings. These wires have proved very satisfactory, and initial troubles, due to crystallization of the metal through vibration, having been overcome, this is now the commonest form of bracing. Hard drawn piano wire has disappeared, but cable is still extensively used, particularly in types where high performance is not essential.

The design of interplane struts has undergone certain changes. The earlier aeroplanes had struts of streamline section made from solid spruce, and occasionally steel tubes faired off to a streamline form by light fairings were used. With the growth in size of aeroplanes and the increasing scarcity of suitable wood, built up or laminated struts were used. Also. with the standardization of steel tubes for aeroplane work, and an enormously increased production of these, this form of strut became very popular. It is a most efficient construction, particularly for the landing chassis.

Internal bracing wires have gone through much the same process as the main-plane bracing wires-at the commencement 
of the war, piano wires were invariably used, but these have now almost universally been superseded by swaged rods, screwed at the ends for fitting purposes.

Juring the war also, the scarcity of silver spruce occasioned the development of new methods of spar construction. These were originally always in one length from the centre section to the wing tip and spindled from a solid section. The first effect of timber shortage was to introduce a system of splicing, and much experimental work was carried out to determine the best form of splice to be used. The result of this work was that a straight scarf joint sloped 1 in 9 was adopted as a standard. This scarf was glued, pegged and wrapped with fabric. Its efficiency was high when compared with the solid spar, and it was a simple job when considered from a production point of view.

The splicing of spars was not found sufficient to overcome the timber shortage, and the need became evident for some change in design by which small scantling timber could be used, even for the spars of large aeroplanes.

Further experimental work was put in hand, this time to determine the effect of laminating spars, i.e., glueing thin strips together, and from this built-up section constructing spars in the ordinary way. At the same time experiments were made on box spars, i.e., the spars instead of being made of the common " $I$ " section were made in box form, the flanges and webs being formed of separate pieces of materials, glued and bradded together. Both the laminated and box spars were found to be very successful, and both types were immediately put into service. No trouble has been met with from their use. Indeed, it is probable that better quality spars are obtained from this means than by cutting from the solid, at any rate for large aeroplanes. The smaller the scantlings, the easier inspection becomes, and the more guarantee is there that first class material only is being used.

Splicing and the building up of spars have proved such successful innovations, that there is no doubt that these methods of spar construction, introduced purely as war measures to overcome the serious timber shortage, will remain as standard in the future.

Fuselage Construction.-Fuselage construction has undergone very few changes, during the period of the war, as regards methods. Larger aeroplanes have been built, and this has naturally meant greater attention to the construction, but the broad lines of design have remained fairly well the same. 


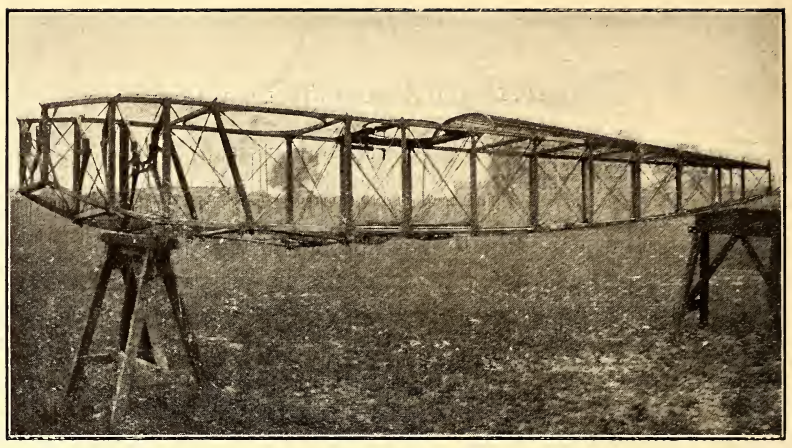

Fig. 8.-Braced N. Girder Fuselage. Fairey,

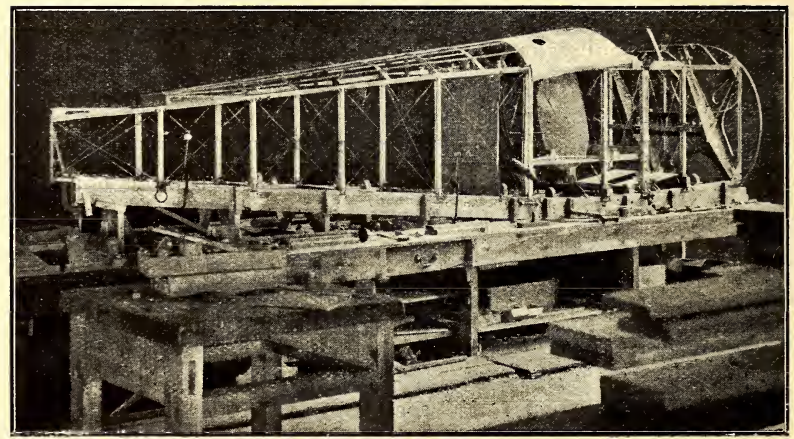

Fig. 8a.-Braced N. Girder fuselage. Camel.

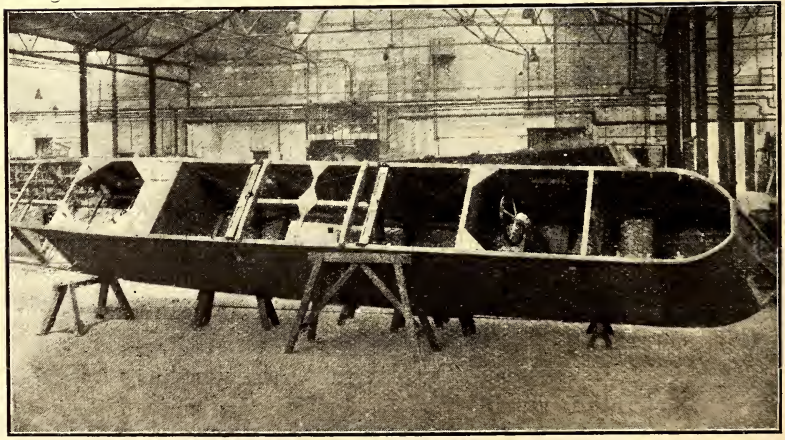

Fig. 9.-Three-ply Covered Fuselage. De Haviluand 10. 
There are three principal types of construction adopted in present day practice.

(1) The braced $\mathrm{N}$ girder fuselage (Figs. 8 and $8 \mathrm{~A}$ ).

(2) The three-ply covered fuselage (Fig. 9).

(3) The monocoque fuselage (Fig. 10).

The first of these consists of four longerons, or fore and aft rails, braced by a system of struts and diagonal wires in all four faces. Fabric covering completes the structure. This is the commonest type of design.

The second system retains the longerons and the vertical and horizontal struts, but in place of bracing wires and fabric, thin three-ply is glued and bradded to the framework.

The monocoque fuselage dispenses with the longerons and consists of a single sheet of three-ply or veneer moulded to shape on formers.

As a general rule, three-ply frames are provided as bulkhead bracing at intervals along the length. There are several varieties of this construction, but the essence of them all is the tubular construction of thin veneer, the formers or bulkheads merely being inserted to stabilize this skin.

Of the three methods of construction, the first and third were known and adopted before the war, and modifications have been more in the nature of improvements in manufacture than in fundamental alterations in principle. The second method was, I believe, first used by the Germans in their early Albatross scout at the beginning of the war, but has since been used with great success by British designers, notably in the case of the De Havilland designs.

Monocoque Construction.-The monocoque method of construction was adopted by the Germans at an early date and was later almost universally used by them. The probable reason for this was their ample supply of high orade three-ply, rather than any constructional or aerodynamical advantages which they attached to this method of construction.

The chief advantage from the service point of view, of a monoconue method of building fuselages lies in its invulnerability to casual bullets. In an ordinary fuselage a bullet striking a main longeron or strut might quite possibly cause the structure to collapse, whereas a monocoque will stand up to any number of bullets. A disadvantage is that truing up becomes difficult and special arrangements are necessary to overcome this defect.

Our supplies of three-ply were deficient almost up to the end of the war owing to the failure of the Russian supplies, 


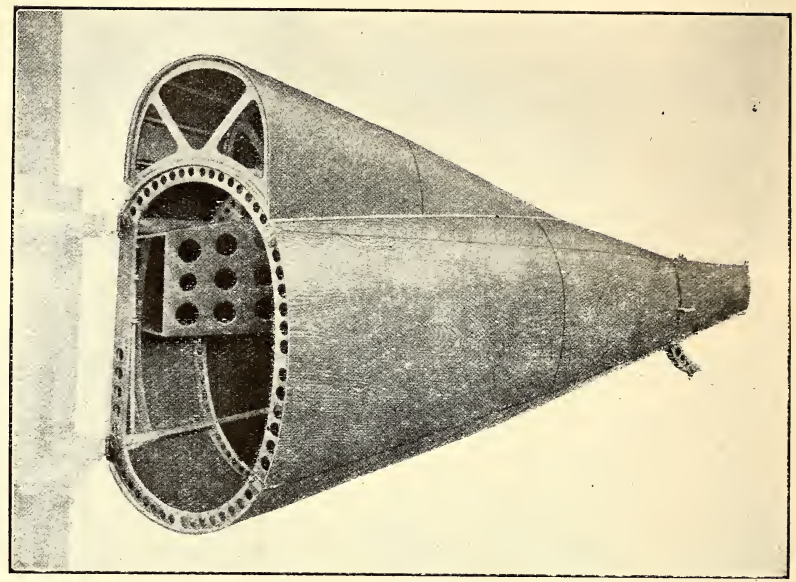

Fig. 10.-Typical Monocoque Fushlage (Parnall Panther).

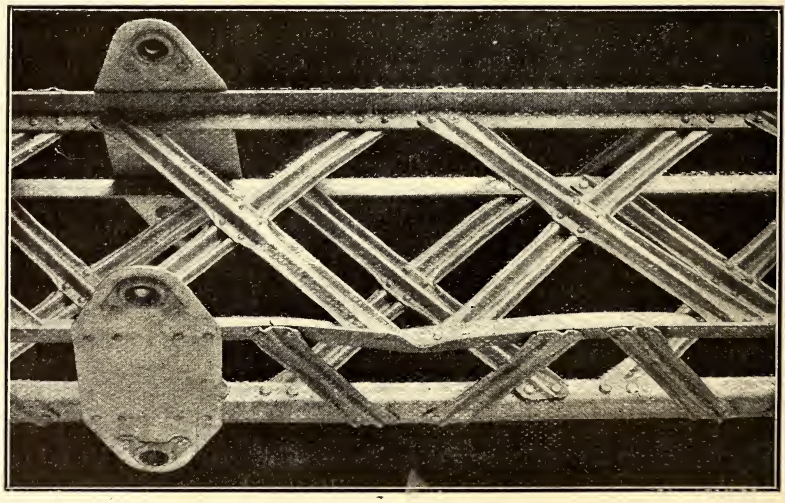

Fig. 11.-Metal Construction. Vickers Duralumin. 
and this no doubt had a considerable influence on our designers and manufacturers. One of our firms did develop a very simple method of constructing in three-ply, which would have admitted of a large production, but the particular aeroplane was not adopted for, other reasons.

It was thought at one time that the rounded fish-like form of monocoque would considerably lessen air resistance, and would enable a higher speed to be developed. 'The importance of this, however, has been a good deal exaggerated; the advantage gained is not worth very much.

The monocoque construction offers great opportunities of development for commercial aeroplanes, as it leaves the space inside the skin free from obstruction, a very considerable advantage when carrying mails, goods or passengers, and in this respect it has a great pull over the standard braced fuselage where diagonal bulkhead bracing wires occur at every panel. It has also a considerable advantage in the almost complete absence of metal fittings, making for ease of construction.

The largest aeroplane yet built-the Tarrant Tabor-has a fuselage eleven feet in diameter, which has been built on a modification of this principle, the skin being made of layers of thin laths glued and tacked over formers until set. The skin is stabilized by latticed hoops of wood, and the resulting structure is a very light and strong fuselage with the whole of its interior free from obstruction.

The regrettable accident to this machine on its first trial in no way reflects on the basis design of the machine.

In a flying boat, the hull has to function both as a boat, as a landing carriage, and as a fuselage, and it is not uncommon to hear of the seaplane, as a class, being under serious disadvantage to the aeroplane because of the heaviness of its hull. Our experience during the war has brought us to the point of being able to state that a well designed hull is no heavier than a fuselage and landing carriage, and that sea aircraft are therefore under no disadvantage under this heading as compared with land aircraft.

Metal Construction.-There is no doubt that the future of metal construction for aircraft is very promising. The amount of work and time entailed in designing metal structures is very much greater than that required for wooden ones, owing to the experimental work involved. There is also the difficulty of introducing modifications during the production stage, modifications which were continuous, during the war, owing to Service demands to 
meet new and unexpected conditions. During the war, therefore, metal construction has not been generally adopted. Its future, however, was clearly seen, and a great deal of experimental work was done, principally in connexion with the Avro Training aeroplane. At the end of 1917 , as I have said before, there was a shortage of good quality timber, and a still greater shortage was foreseen as probable in the future, owing to the demands of the enlarged programme. A big effort was made to employ metal for the Avro which was absorbing something like one-third of our total wood supplies, and which was a thoroughly well established type, with an assured future for training purposes.

The experimental work done in this direction was very considerable and much interest was aroused among manufacturers. As a result, it can be definitely stated that, even for such a small type, the use of metal enables the wings to be made slightly lighter and distinctly stronger than is possible with the best quality spruce. The experimental work necessary to get at this result was so extensive and protracted that the type was not actually produced in metal in quantities, but the information obtained was of the utmost value and was well worth the effort.

Experimental work was also carried out in the application of metal construction to larger aeroplanes, and there is no doubt that the constructional gain both in weight and in reliability will be more marked in the case of large types than in small ones. The uniformity of strength obtainable in metal will give it a marked advantage over wood, and will enable aeroplanes to be made without such large allowances for variations of material.

The Germans, on the other hand, were driven to the necessity of employing metal at an earlier date than ourselves, and although they never turned out any metal structure which would have satisfied us, this form of construction was very considerably employed. Their A.E.G. twin engine bomber was almost entirely made of metal, but it was relatively heavy and allowed only a very small weight of bombs or fuel, before it became dangerously overloaded. For the spars they used high tensile steel tubes which are not altogether satisfactory for use as a combined strut and beam.

At the end of the war there certainly did appear an all-metal German aeroplane which was called the Junker monoplane. This was of a quite novel type of construction, the wings being covered with corrugated aluminium sheeting and having multitudinous internal tubular bracing. A very thick wing section was employed. The performance was not good and it is doubtful 
if the type would have really been of any serious value, but as a piece of construction it showed considerable merit.

The Progress of Design and Con:truction of Propellers.- The screw propeller has for many vears been used as an organ of propulsion for marine craft. It was not, therefore, a totally new problem with the advent of aircraft. In its use on aircraft the propeller altered its shape, and the blades became longer and narrower as compared with marine practice.

At the outset trial and error methods were applied, and a suitable propeller was arrived at only after the trial of a large

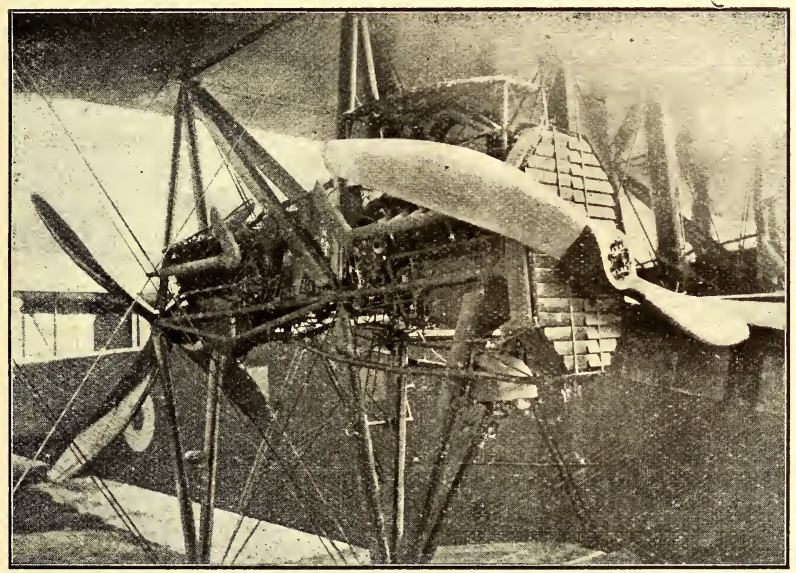

Fig. 12.-Tandem Propellers. Handley Page V.1500.

number of designs. The variations met with in aircraft work are very great. At the present day, aircraft speeds vary from 40 m.p.h. in the airship to $150 \mathrm{~m}$.p.h. in the aeroplane. The engines vary from 40 horse-power to 600 horse-power, while the propeller revolutions vary from 500 to 2,200 per minute. With such wide variations in conditions a surer and quicker method of arriving at the best results was demanded. Curiously enough, aircraft propeller designers had recourse to a method devised by M. Drezweichi in 1892 for the design of marine propellers, which consisted of a mathematical analysis treating the propeller blade as a rotating wing. The method was tested at the National 
Physical Laboratory, and is now in general use, with the result that it is rarely necessary to test more than two propellers to arrive at the desired result. Frequently the result is obtained with sufficient accuracy in the first trial design.

The efficiencies now obtained in aircraft propellers are high, being 75 per cent. as an average, and frequently 85 per cent. under optimum conditions.

As regards construction, the peculiar vibration and variation of torque prevented the use of metal, which quickly fatigued and failed. For this reason and also for quickness in manufacture, wood became and still is the principal material used.

Only the highest class material was suitable, for, at the speed at which modern aircraft engines run, the radial pull at the root of a propeller blade may be as much as 5 tons, while at the same time the propeller has to pull the aircraft along, inrolving bending moment due to forces of as much as $\frac{1}{2}$ ton pei blade. The stresses due to these combined forces were satisfactorily met with for the smaller powers, but at one time it was thought that the size of engines would be limited by the maximum power which could be transmitted through a single propeller. And such might have been the case, had it not been discovered that instead of the stresses due to these two forces adding to each other, it might be arranged so that the bending stresses due to centrifugal action would completely neutralize those due to the thrust.

The only limits now imposed on propeller design are:-

(1) Tip speed.

(2) Constructional limitations.

As regards the first, experiments have shown that a tip speed equal to the speed of sound should not be exceeded, and to this speed we are rapidly approaching. In the standard propeller for the American Liberty engine in the D.H. 9a, the tip speed is 880 feet per second as compared with 1,050 feet per second for sound. This difficulty, however, is met by gearing the engine so as to reduce the propeller speed. Provided the engine is suitably geared so that the tip speed does not exceed 900 feet per second, there appears to be practically no limit to the amount of power which can be transmitted through a single propeller. Even with present day methods of construction it is safe to say that 2,000 horse-power can be transmitted through a propeller mounted on an aircraft flying at 80 m.p.h. and as much as 6,000 horse-power on an aircraft flying at 150 m.p.h. 
As regards the question of commercial construction, development has been along normal lines; improvements have been made in the details of manufacture such as the glueing of the numerous wood laminations, and the protection of the blade with fabric and metal edgings; and the general result has been a better and more reliable article. Severtheless, the use of wood is not wholly satisfactory, especially for future commercial work, involving flight through tropical countries, and we therefore look forward to the solution of the problem of the metal construction of propellers.

Division into Types. - When the war began the only aeroplane function which was considered seriously by the Army Authorities was that of reconnaissance, and there is no doubt that the B.E. $2 \mathrm{~A}$, which was developed by the Royal Aircraft Factory for this function was an excellent aeroplane, thoroughly well adapted for its work.

lieconnaissance Aeroplanes.- These early aeroplanes were not intended to carry any military load other than crew, but almost from the very sitart of the war the military load required began to increase, with the result that all through 1915 and well into 1916 our reconnaissance aeroplanes were over-loaded with all kinds of equipment, such as guns, gun mountings, cameras, wireless apparatus, etc., which were attached to any available part internally or externally. In order to carry out their requisite functions, this additional equipment was necessary, but it naturally meant a very considerable reduction in performance. The speed was brought down 10 or 15 miles an hour, while the extra weight and resistance had a very serious effect on the rate of climb. This is shown by the diagrams giving the performances at the different periods of the war ; it not until the latter part of 1916 that any appreciable improvement in performance can be seen, and then both the speed and the climb go up rapidly.

It was at this period that the special military aeroplanes, designed subsequently to August, 1914, first came into use, and in these full allowance was made for all equipment to be carried. The increase in performance was due not only to the higher power engines used, but also to the fact that the aeroplanes were designed to carry the equipment as far as possible internally, thus avoiding all unnecessary resistance.

As aerial tactics developed, the roles of the pilot and observer altered, and the latter practically confined himself to being a pair of eyes in the back of the pilot's head, whereas the pilot had 


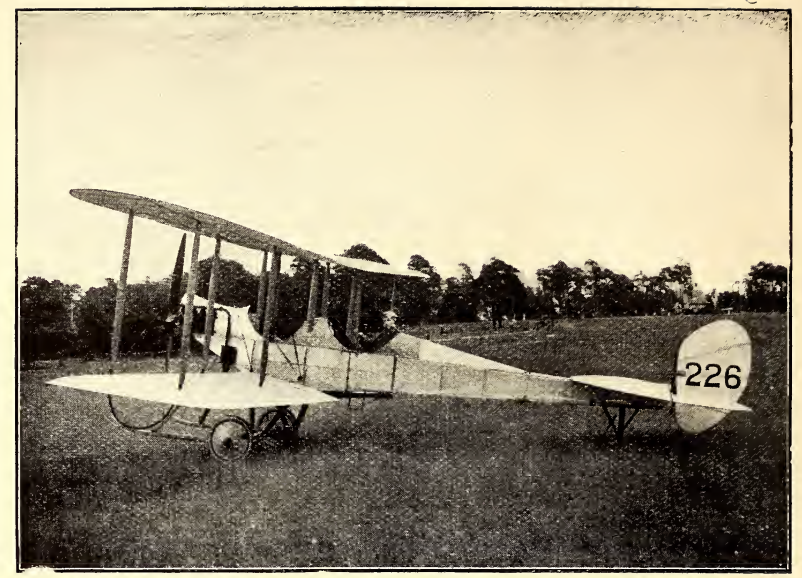

FIG. 13.-B E 2A.

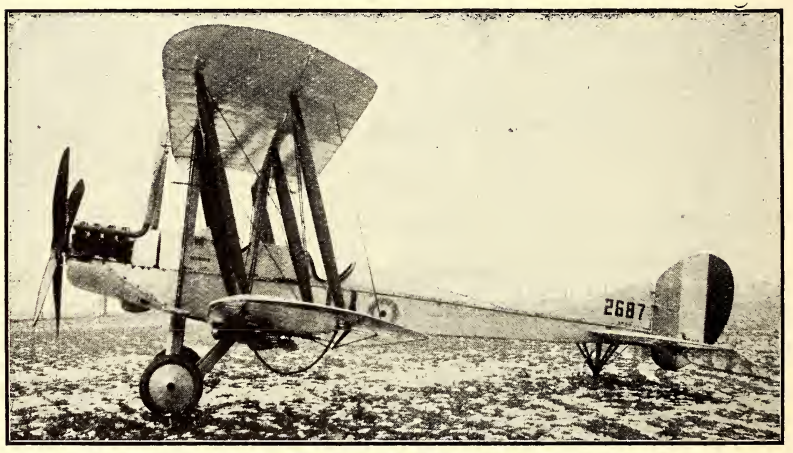

Fig. 14.-Reconnaissance Machine. B.E. 2c.

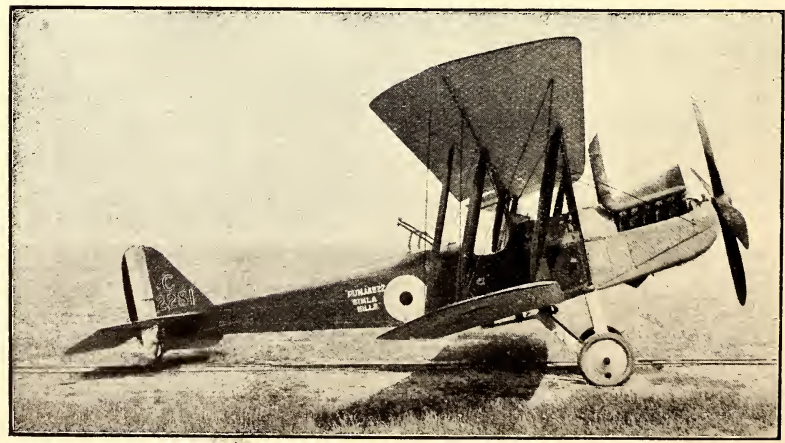

Fig. 15.-Reconnaissance Machine. R.E. 8. 
to do all the reconnaissance, artillery, spotting, etc., as well as Hy the aeroplane.

Single-seater Fighter Development.-As well as doing one's own scouting, it was necessary to stop the other side doing his or rather to stop him from taking his reports home. This meant fighting, and fighting meant guns and better performance. The early aeroplanes were soon fitted up with a. Lewis gun fixed so as to fire over or at the side of the propeller disc, and actuated by a Bowden wire. This gun was at first fixed to fire upwards at a considerable angle to the line of flight, necessitating an oblique method of attack. Then later, in order to enable the aeroplane itself to be aimed directly at the objective, the gun was mounted on stands and in a line practically parallel to the propeller shaft. It was found that, by aiming the aeroplane itself rather than an independent gun, shooting was more accurate. The attachment of all this gear and weight to machines which were not designed for them was a very serious handicap, and performances were reduced 15 or 20 per cent. on speed and ceiling.

Late in 1915 the Germans brought out a system of synchronizing the trigger with the engine, so that the bullets went between the blades of the propeller. This was a great improvement as it enabled the gun or guns to be fixed alongside the engine, within easy reach of the pilot, and offering very much less wind resistance. The Vickers gun was quickly adapted to work in a similar manner on our Tractors, and by the late summer of 1916 our single-seater fighters were on a par with the Germans'. During this period, in addition to the Tractors with exposed Lewis guns, we had been making very considerable use of small single-seated pushers of remarkably good performance considering the difficulties of the proposition.

The characteristics of the Sopwith Pup, our first good tractor single-seater, were very light surface loading, a small but good rotary 80 horse-power French engine, and every scrap of unnecessary weight eliminated by careful design. The view, particularly overhead, was not very good, but the aeroplane was so handy fore and aft that this did not interfere very seriously with its fighting qualities. This type lasted a very considerable time before it was superseded, which, in view of the comparatively small horse-power, was remarkable. During the period in which this type was in use fighting acrobatics advanced to a marked degree, and in the next type an effort was made to increase view and manœurrability. This was the Sopwith triplane with 


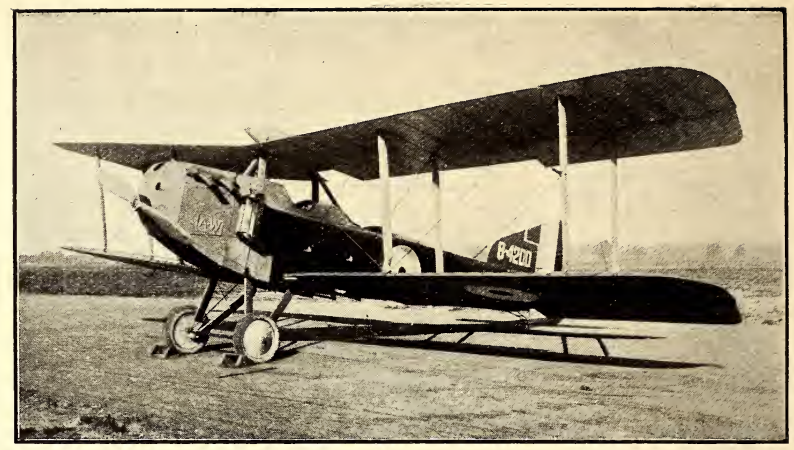

Fig. 16.-Artillery Machine. Armstrong-Whitworth F.K. 8.

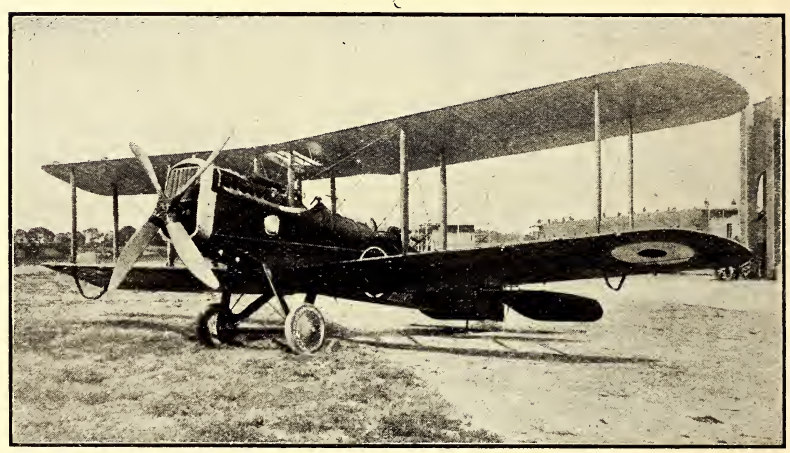

Fig. 17.-Artillery Machine. De Havilland 4; Eagle ViIí.

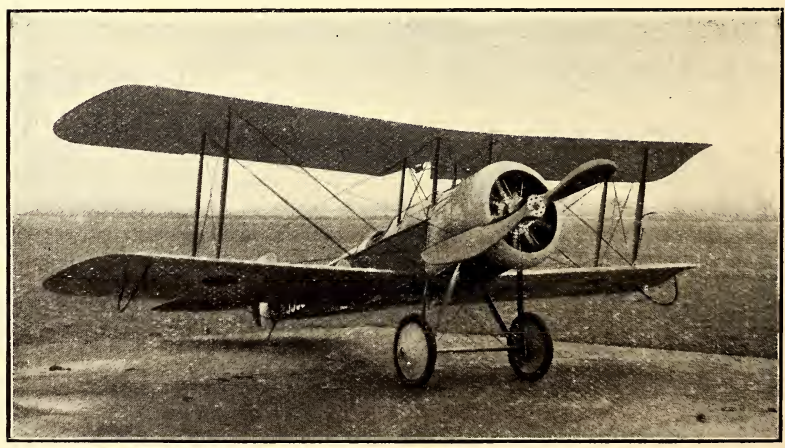

Fig. 18.-One-seater Fighter. Bristol Scout. 


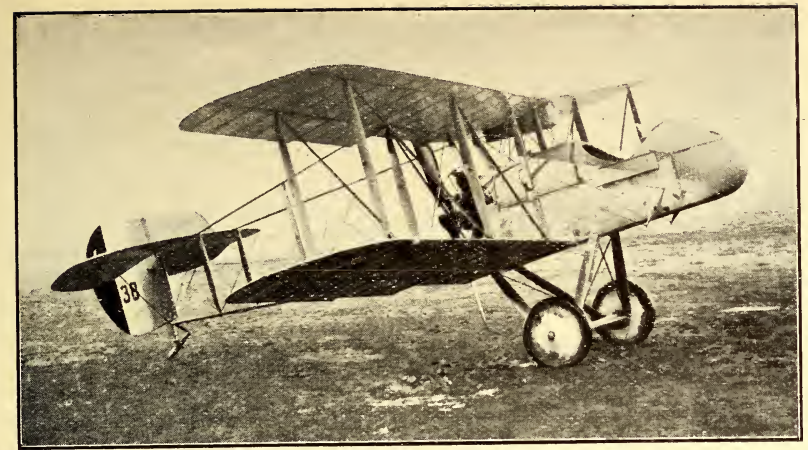

Fig. 19.-One-Seater Fighter. De Havilland 2.

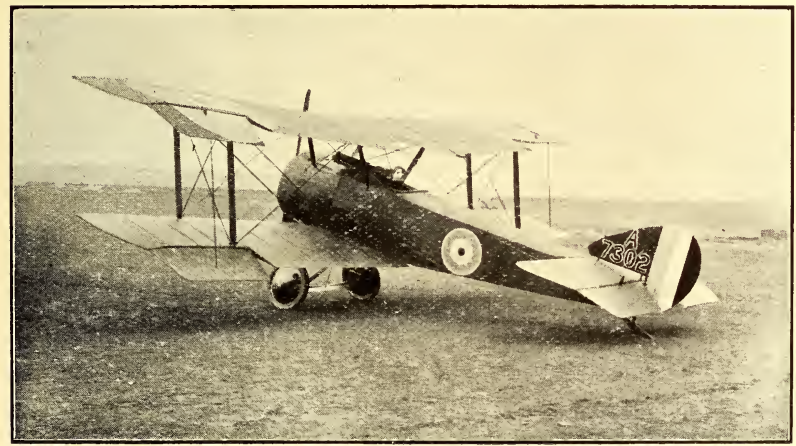

Fig. 20.-One-seater Fighter. Sopwith Pup.

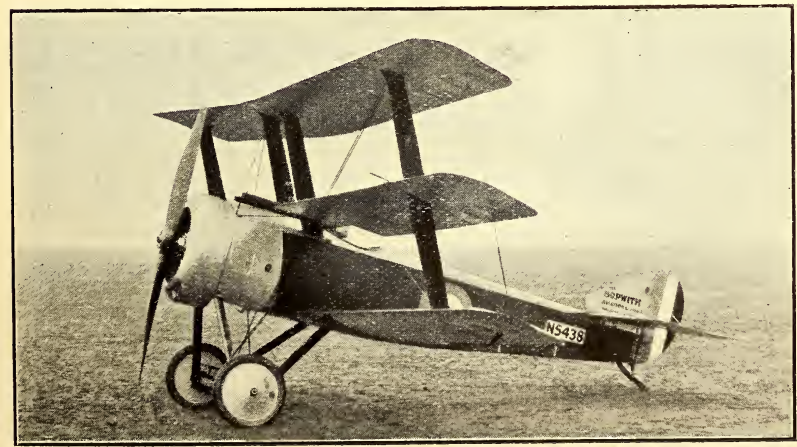

Fig. 21.-One-seater Fighter. Sopwith Triplane. 
another French engine of 110-130 horse-power, and its characteristics can be clearly seen in Fig. 21.

The loading per square foot had increased, but the loading per horse-power had decreased considerably, and the performance was better. Some of the aerodynamic disabilities of the triplane were overcome by the pronounced forward stagger and the use of a single strut. This single strut system increased the difficulties of manufacture and repair, particularly as regards truing up. Both this aeroplane and the one before it were provided with only one synchronizing gun, and the rate of fire was consequently slow.

In aerial fighting, the time in which it is possible to hold the enemy on the sights is very short, and one gun was found insufficient, apart from the considerable chance that the one gun might jam at the crucial moment.

In the next type, which was in design at the end of 1916, and came into production in 1917, we see the influence of these considerations upon the mind of the designer, who by the way was Mr. Hawker of Transatlantic fame. We have here a very simple and, though unstable, an easily controllable biplane with two guns. Enormous numbers of this type were produced in the course of the next year or two with French and English engines which increased in power" up to 150 horse-power. The type was nicknamed the "Camel" because of the curious hump in the fuselage.

The next type on our list is the S.E. 5 designed at the Royal Aircraft Establishment, Farnborough. This is really a direct descendant of the B.E. $2 \mathrm{~A}$ with which we started. It was a very long time coming into general use, principally owing to delays with the engine, a 200 horse-power water-cooled French Hispano. Opinion was by no means unanimous as to the fighting value of this aeroplane compared with the Camel, and each type had its school of adherents. The S.E. 5 had a better performance, particularly at a height, was stable and manœuvrable, very easy to fly, and had better visibility due to the pilot being farther hack. On the other hand, it was much more difficult to produce and the engine and its accessories gave a great deal of trouble both at home and in the field.

By this time we had reached a point where the performance of our aeroplanes was very considerably in advance of that of the Germans, who were cramped by their non-elastic engine policy.

The next type to come into general service was the Sopwith 


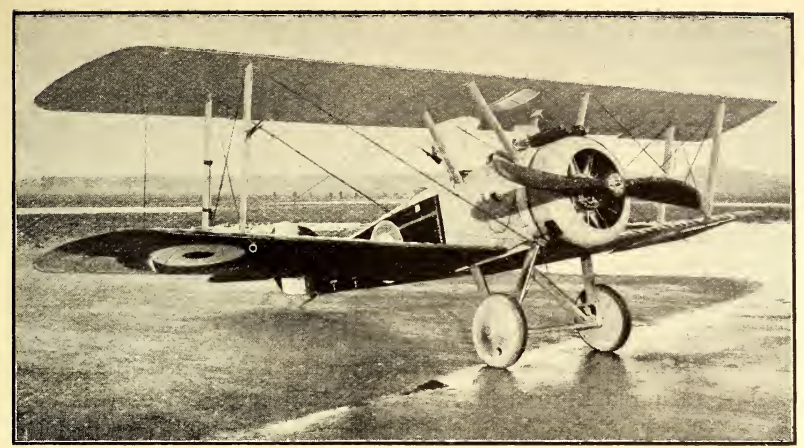

Fig. 22.-One-seater Fighter. Sopwith Camel.

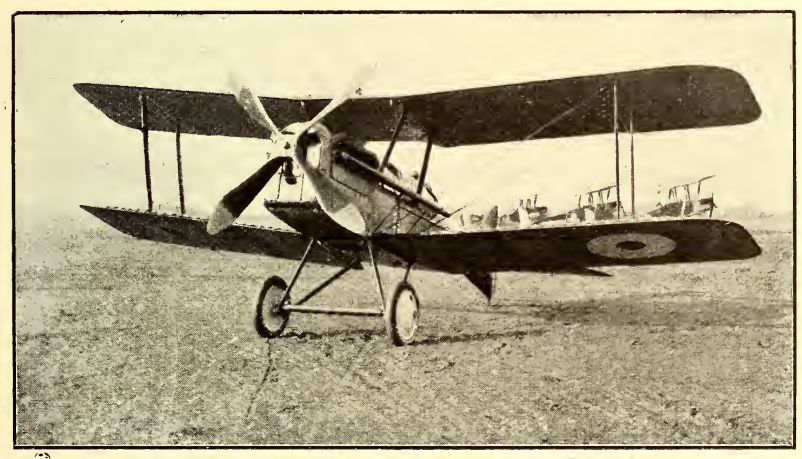

Fig. 23.-One-Seater Fighter. S.E. 5.

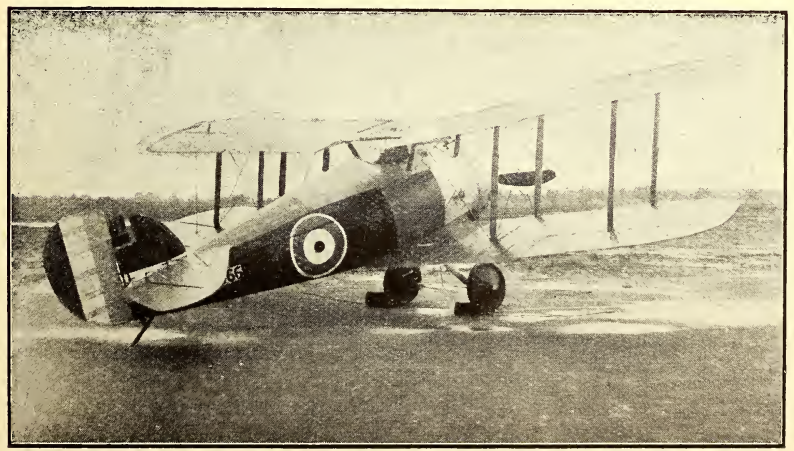

Fig. 24.-One-seafer Fighter. Sopwith Snipe. 
Snipe. The engine here was a 200 horse-power B.R. 2 of British design. It would appear that this size of air-cooled rotary engine has reached, if it has not in fact surpassed, the maximum size for efficiency. The performance was rather disappointing. and must be attributed to the enormous engine diameter and air resistance. Sereral competitive aeroplanes from different maker's were tested simultaneously with this one, and the results were practically all the same. You will notice that the control surfaces are balanced. In this way the necessary manouvrability was maintained, although the weight of the aeroplane had reached rather a high figure. The actual selection of this type was largely governed by the engine position which entailed the placing of orders on a production scale before trials of the actual engine and aeroplane were carried out.

Finally we come to the Martinsyde F. 4 which, although in production, was never used at the front previous to the signing of the Armistice. This had another water-cooled engine-275 horse-power Rolls Royce of high efticiency. Both aeroplane and engine were very good, and although the former was heavy and somewhat large, it was wonderfully mancuvrable. The performance reached was very high-over 130 miles an hour at 15,000 feet with a climb to that height in 12 minutes.

The increase in speed and climb from period to period is shown on Fig. 54.

Two-seated Fighters. Apart fiom the particularly interesting case of the single-seaters, there developed from the use of the original reconnaissance type, a demand for, and a supply of two-seated fighting aeroplanes, which could do their reconnaissance work and defend themselves, if attacked. As the best method of defence has always been and will be, to attack, these machines which were in principle defensive, became very effective in the offensive. Our two-seated pusher fighters, such as the Vickers or the F.E. 2s, gave a very good account of themselves, until the time came when their poor performance, as compared with the tractors, put them out of date.

'The first really good two-seated tractor was the $1 \frac{1}{2}$ Strutter, so called by the Sopwith Co. because of its peculiar wing strut system. This aeroplane was, and still is, one of the most efficient ever designed, and for its engine power (130 horse-power Clerget) it has never been surpassed. In it the pilot was placed as close up against the engine as possible with a very fine view ahead and downwards. The gunner was now put behind him with a rotatable Lewis gun turret. He had a very good view 


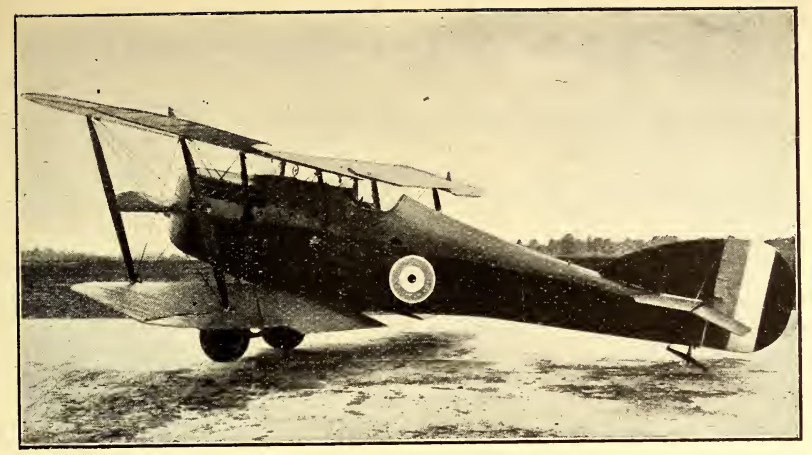

Fig. 25.-One-seater Fighter. Martinsyde F 3.

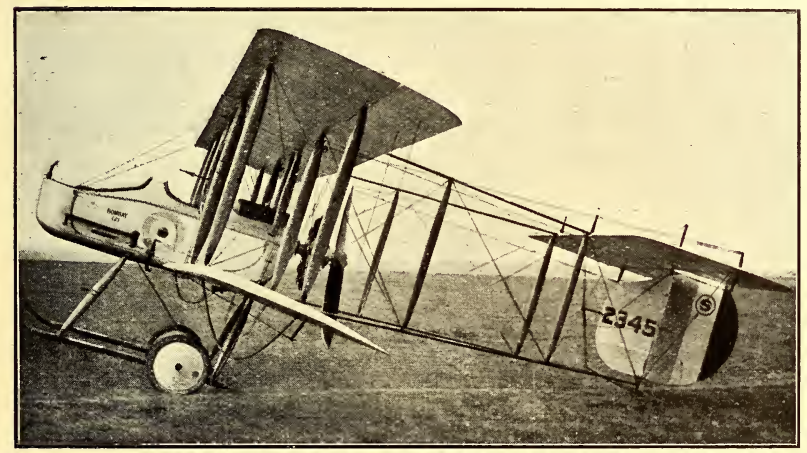

Fig. 26.-Two-seater Fighter. Vickers Gun Bus.

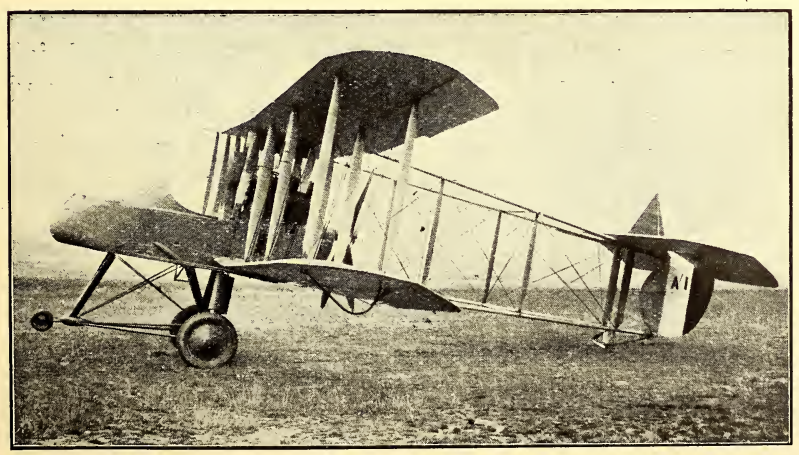

Fig. 27.-Two-seater Fighter. F.E. 2B. 
downwards and all round the rear. This arrangement, which is, in principle, still standard, gave a very manœuvrable aeroplane owing to the concentration of the weights; and on account of its high performance the type became a very effective offensive weapon.

Early in 1917 there appeared another two-seated fighter where the qualities enumerated above were still further developed. This was Captain Barnwell's Bristol Fighter with a Rolls Royce Falcon engine. Both aeroplane and engine were exceedingly good. The view for the pilot was improved by putting him farther back and higher so that he could see over the top plane, and being closer to his gunner, they could communicate better. Close communication in this sort of fighter is a very vital matter, and probably this type did more to establish our superiority over the enemy than any other.

Bombers.-Reverting to our original B.E. 2As., from which we have seen the development into one-seated fighters and twoseated fighters, we can trace also the development of the bomber. This was the type of aeroplane first used for bombing purposes, as soon as bombing, as a useful and military function, was appreciated. There were sporadic efforts at bomb dropping bv 80 Gnome Avros, but when it developed into organized attacks with numbers of aeroplanes, the original reconnaissance type was used. As soon as the real requirements of this work were understood specially designed aeroplanes appeared. In the early types the bombs were fitted in all kinds of ingenious but crude ways, with pieces of string and cutting knives, etc., and the attacks were made by diving to a low height and planting the bombs by the pilot's judgment. Although great efforts were made in the training of bomb droppers and in the perfection of sighting and releasing apparatus, etc., accuracy from a height was never really obtained, and experiments conducted towards the end of last year, proved conclusively that the only way to hit any isolated object with certainty, was to dive to a low heioht before letting go the bombs. Nevertheless the moral effect of bombing is immense in disturbing industrial work and the manufacture of munitions.

With the introduction of the B.E. 2c., systematic bombing of the enemy's positions was carried out, but this aeroplane was capable of making comparatively short raids only, and when Ingred with bombs could not carry an observer. With its moderate speed it was rather an easy prey for enemy scouts under such circumstances. 


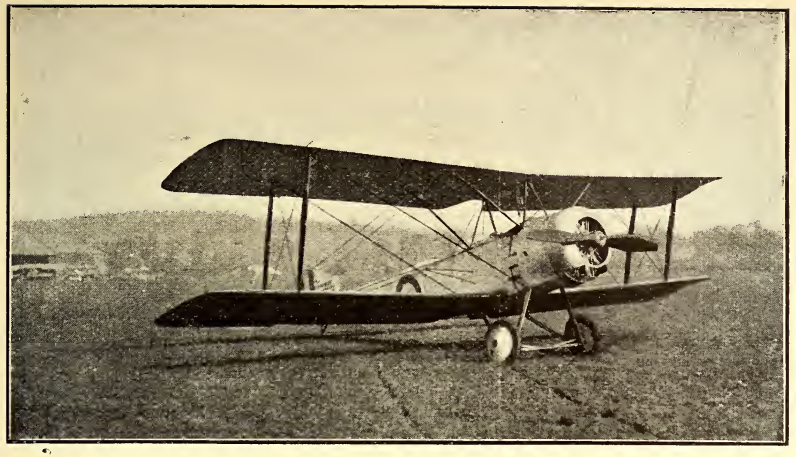

Fig. 28.-Two-seater Fighter. Sopwith $1 \frac{1}{2}$ Strutter.

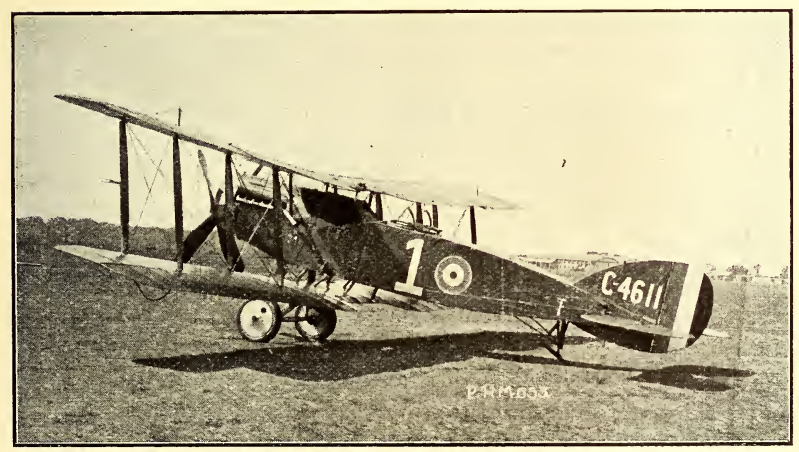

Fig. 29.-Two-seater Fighter. Bristol-Rolls-Royce.

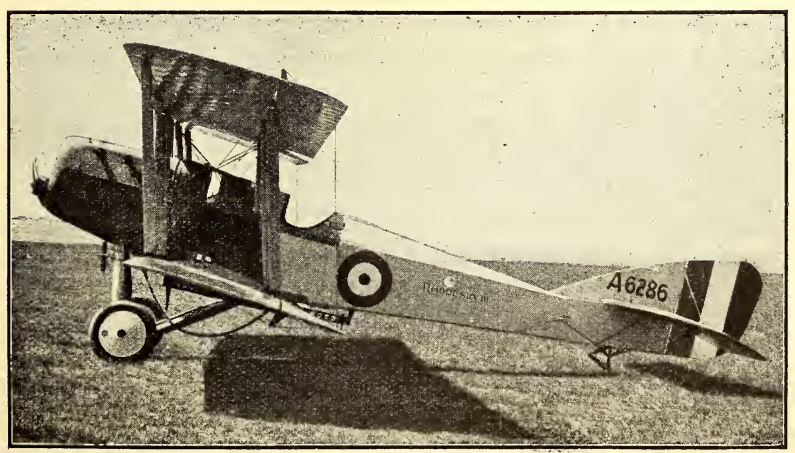

Fia. 30.-Day Bomber. Martinsyde 160 H.P. 
The Martinsyde single-seater bomber with the 120 and later the 160 Beardmore engine was a distinct advance as regards range, while its greater speed made it a much better fighter.

As bombing developed, a subdivision of types into definite branches took place. These were day bombers, short distance and long distance; and night bombers, short and long distance. From an aerodynamic point of view the design of a high speed, long range weight carrying aeroplane is an exceedingly difficult problem, but it can be fairly stated that our designers, particularly Captain De Havilland of the Aircraft Manufacturing Co., found the solution in advance of those of other countries. His aeroplanes eventually had wing surfaces of high efficiency and of high superficial loading, combined with structures of great cleanliness and low air resistance, and with the most powerful engines available at the time. Owing to their low weight per horse-power his machines could get off easily though at a high speed, and were very fast in the air. On returning home, after the fuel was consumed and the bombs dropped, they could land easily enough, but if by chance they had to land with full load on board, the pilot's difficulties were ronsiderable.

Just as the original B.E. 2, was first used for bombing by day, similarly it was the first type to be largely employed for bombing by night, for which function it was very fairly suited, up to the limit of its capacity, as it was very easy to fly and to land. The weight carrying capacity was, however, not great, as the engine was only 70 to 100 horse-power. When the bigger engines became available this bombing work was taken over by the F.E. 2 pushers which were good weight carriers and had a better view for bomb sighting.

The above remarks apply more to the military flying corps than to the naval service, which made use of any aeroplanes they could get hold of, particularly French ones, such as Caudrons and Farmans. Later, they used the Sopwith $1 \frac{1}{2}$ Strutters, and finally Handley Pages. This latter type was the first really effective design of night bomber, and came into use early in 191\%. Its general features are so well known that it is unnecessary for me to enlarge upon them. When in the Autumn of 1917 a big programme of bombers was laid down this was the type decided upon. The Vickers-Vimy was a later machine of the same general type embodying more recent experience.

At the end of 1917 it was considered to be worth an attempt to make a very long range bomber, to attack Berlin itself, from 


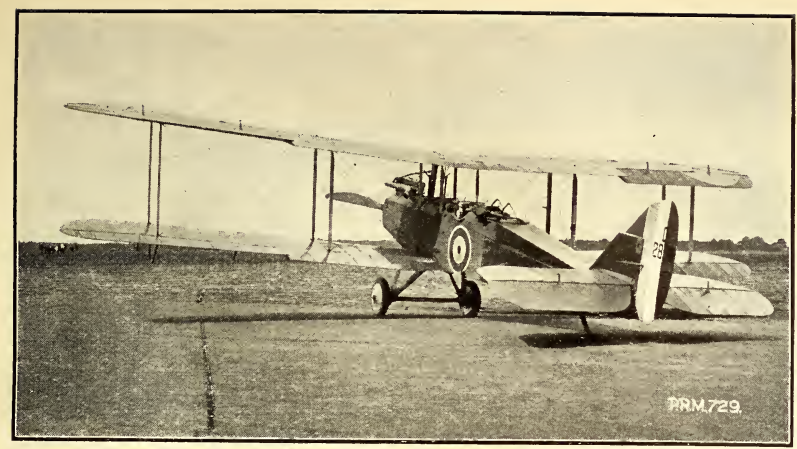

Fig. 31.-Day Bomber. De Havilland 9.

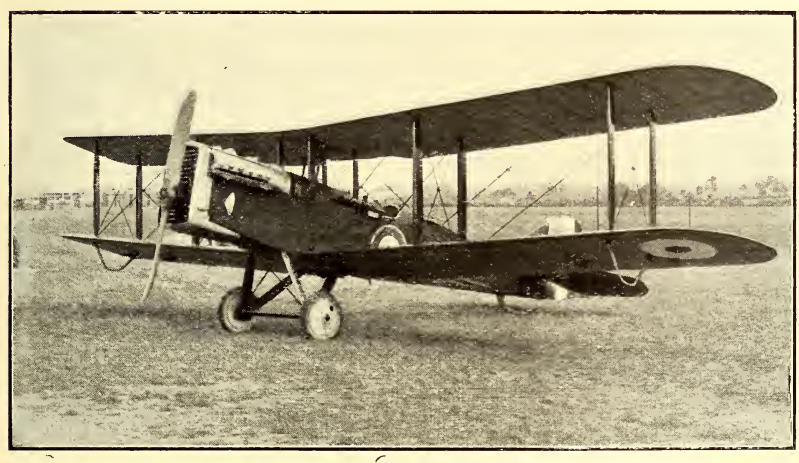

Fig. 32.-Day Bomber. De Haviliand 9a

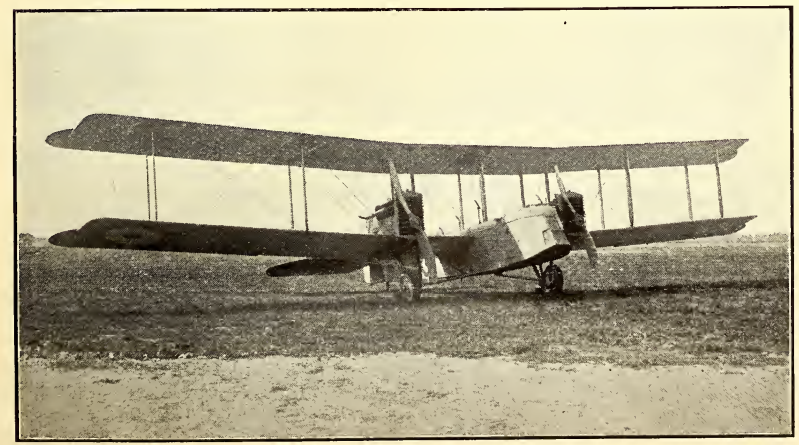

Fig. 33.-Day Boniber. De Havilland 10a. 


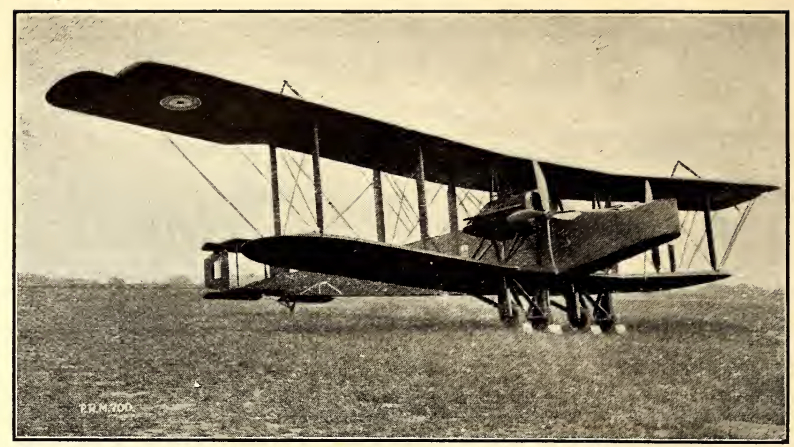

Fig. 34.-Night Bomber. Handley Page 0/400.

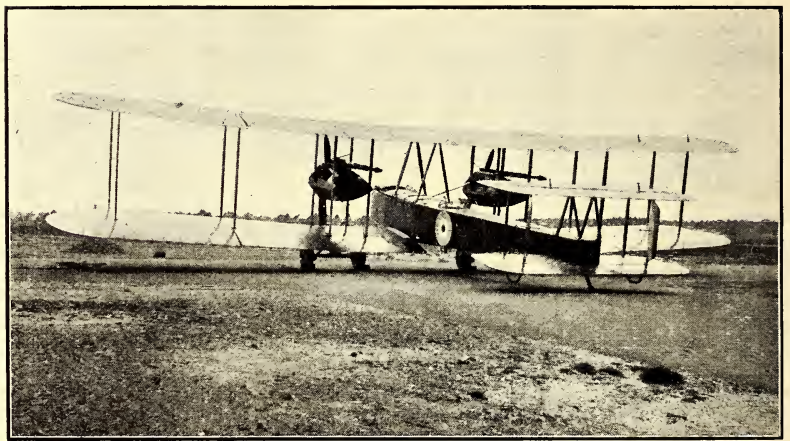

Fig. 35.-Night Bomber. Vickers Vimy.

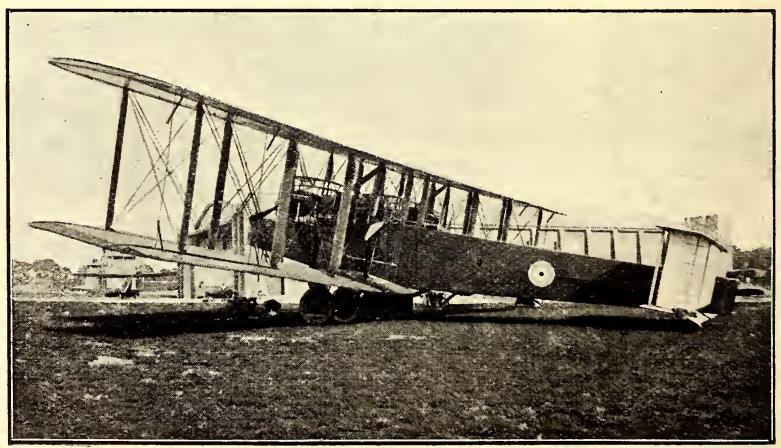

Fig. 36.-Night Bomber. Handley Page V/1500, 
a base in England. The actual point to point distance is about 450 miles and a minimum range of 1,100 miles was decided upon. As the aeroplane would have to fly by day, as well as during the night, it was essential to provide a very complete gun defence system. This meant a crew of 7 , with many guns and much ammunition apart from $\mathrm{W} / \mathrm{T}$ apparatus and bombs. It was clear that it would be necessary to employ a very large aeroplane with powerful motors. The 350 Eagle Rolls being the biggest and best geared engine available it was decided to employ four, using a system of tandem propellers, which theoretical investigation showed to be reasonably efficient. The main lines of the design were quickly arrived at, and arrangements made for the building of a few experimental aeroplanes, by a large firm of shipbuilders in Ireland. In order to get a straight run on the design and to avoid interruption, Mr. Handley Page, the designer, went over to Ireland with a large proportion of his design staff, and after six months very hard work, the first of the batch came over to Cricklewood, to be erected and tested. Many difficulties, particularly connected with the control, were encountered and surmounted, and on the 8th November, three days before the Armistice was signed, two of these aeroplanes were standing ready and fully equipped to start for Berlin.

\section{Ground Fighters.}

Armoured Aeroplanes.-In the very early days of the war the aeroplane had little to fear from enemy action provided it crossed the lines at any height above about three thousand feet, so as $t \mathrm{~s}$ be out of range of ordinary rifle fire from the ground. The introduction of the special anti-aircraft gun, however, very quickly altered this state of affairs, and the aeroplane was driven higher as the accuracy of fire improved; until at the end of the war there was no immunity from danger from A.A. fire at a hoight of 20,000 feet.

For a long time it was considered that the risk of a low flying aeroplane being hit by rifle or machine gun fire from the ground was so great that we should not be justified in using our pilots and aeroplanes in this way. The remarkable escapes experienced from time to time by pilots forced to return across the lines at very low altitudes, however, encouraged the idea that the risks of low flying had been a good deal exaggerated, and a most effectivo mode of attacking the enemy was gradually developed. The first important success in this direction was, I 
believe, achieved by Lieut.-Col. Bishop, V.C. who attacked an enemy aerodrome soon after daybreak. After riddling the officers' and men's quarters with bullets from his machine guns

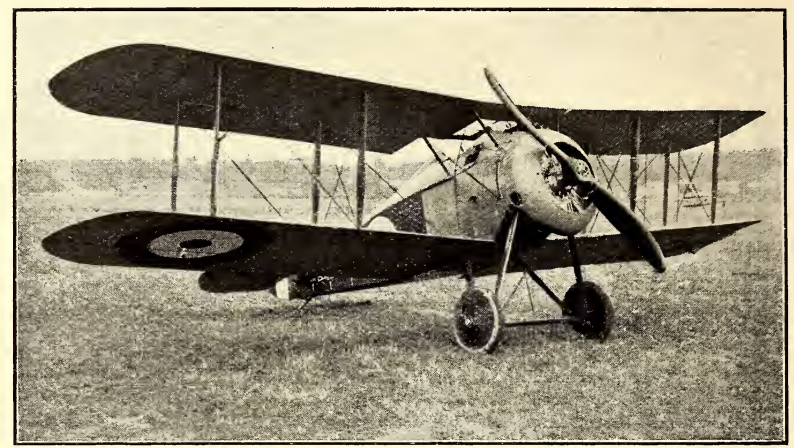

Fig. 37.-Ground Frghter. Sopwith Salamander.

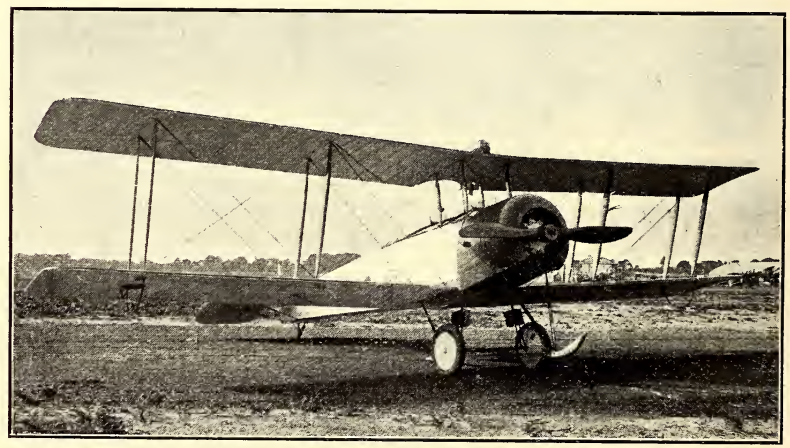

Fig. 38.-Training Machine. Avro.

he turned his attention to the German aeroplanes which had been brought out to attack him. He put two or three out of action on the ground, brought down three in succession as they got into the air, and then returned safely to his own aerodrome. Thereafter this method of attach developed very rapidly, and it 
proved of the greatest value later on, not only in breaking up the dense infantry formations advancing to attack us after March 21st, 1918, but in demoralizing the retreating encmy when we subsequently advanced. A system of co-operation between our low flying aeroplanes and the infantry was also evolved, and this proved of the greatest value in keeping the infantry and the headquarters behind in touch with what was going on in front. The aeroplanes used were the single-seater fighter-especially the light, manœuvrable Camel-for attacking ground targets from very low altitudes; and the standard artillery machine for the infantry co-operation from rather greater altitudes.

Our casualties in these operations were naturally heavy, and the problem of providing a suitable armoured aeroplane arose. As a result the sopwith "Salamander" was designed, and was just about to make its appearance in the field at the time of the Armistice. This was a single-seater fighter with B.R. 2 engine, equipped with two Vickers guns and a very large amount of ammunition for attacking ground targets, while it carried nearly $650 \mathrm{lbs}$. of armour-plates so arranged as to give the pilot and all vital parts of the aeroplane adequate protection from German armour piercing bullets fired from the shortest ranges. In spite of this heavy load it had a speed of $125 \mathrm{~m} . \mathrm{p} . \mathrm{h}$. and was sufficiently manœuvrable for the pilot to make the attack by diving at the target, thus getting the advantage of firing in the direction of flight. Had the war lasted a few months longer this aeroplane would probably have done most effective work in hastening the German retreat.

An armoured two-seater for infantry co-operation was also designed and produced, but like the Salamander it was too late to come into actual service.

\section{Part III.-Progress in Engine Destgn.}

Before 1914 it may be said that aero engine design had merely reached the stage of sufficient reduction of weight/power ratio to enable aeroplanes to fly. Beyond this, practically no special adaptation to aeroplane requirements had been attempted. The development of the aerial arm in the war, however, speedily emphasized the importance of other factors. The extension of the range of operations and the losses of machines, due to engine failure, raised insistent demands for greater reliability, whilst the necessity for easier maintenance called for engines of greater all-round accessibility. 
The rapid progress of flying skill and the adoption of aerial acrobatics in fighting created a demand for engines of short length and quick controllability.

The desirability of carrying out reconnaissance untroubled by enemy attack or anti-aircraft fire focussed attention on the necessity of increasing the ceiling or maximum height of operation. Coping with this most important requirement again produced an improvement of the weight/power ratio, and the ceiling of approximately 7,000 feet in 1914 was increased to nearly 30,000 feet by the beginning of 1919. It must be remembered also that the diminished density at great height decreases the amount of oxygen taken into the engine, and therefore the power which the engine can deliver. At 15,000 feet, for instance, a 300 horse-power engine can only deliver about 200 horse-power.

The extension of bombing activities at long ranges emphasized the importance of the study of the fuel consumption which, for a flight of 6 hours, amounts to a large weight per horse-power. The question of the thermal efficiency had therefore to be studied in conjunction with the weight/power ratio, so that engine speeds increased whilst the aerodynamic requirements of the machine demanded reduced propeller speeds.

Long before the end of the war the power requirements of some aeroplanes and seaplanes had far outstripped the possibilities of any one engine, so that machines possessing two, three, four, or even more engines were in service or being built.

An important factor affecting aero engine development is the time which is required to produce a new design. Generally about eighteen months would have to elapse between the commencement of the design and a useful flow of reliable production engines. During most of this period no useful practical experience can be obtained as to the qualities or defects of the new design, and by the time bulk experience of its behaviour in service is available, it is necessary to supersede it by another more advanced type. Less than half the time is required for the development and trial of an aeroplane design, so that the aeroplane is generally well ahead of the engine for which it is designed.

In 1914 our aircraft engine position was by no means satis factory, and we depended for a large proportion of our supplies on other countries, principally on France, whose Gnome and Renault engines were pre-eminent. Great efforts were immediately made to extend our sources of design and supply, 
and by the end of the war British engines had gained foremost place in design, and were well up to requirements as regards supply.

Many of the earlier designs were considerably influenced by previous automobile engine practice, but a wide divergence of design and detail soon took place due to the entirely different nature of the conditions to be faced. In automobile practice silence and good carburation over a wide variation of speeds and loads were the most important features, whereas those points are of small importance for an aircraft engine. The task of the aero engine designer was still further complicated by the fact that the order of importance of the various features of the engine is different according to the class of machine for which the engine is being designed. Certain entirely novel conditions had to be met and their attendant difficulties overcome. For example, an aero engine must have the ability to function in practically any position and, for a time at least, when completely inverted. This requirement has had a far-reaching effect on the lubrication system of aero engines, as it practically precludes the carrying of oil in the crankcase.

The shape of the engine is a matter requiring careful consideration for aircraft, as head-resistance, accessibility, and small moment of inertia are all features of considerable importance dependant on the shape. The wide ranges of temperature and pressure tiorough which an aeroplane may pass affect the carburation, the cooling system, the lubrication system, and even the ignition to a very serious degree. An aeroplane may undergo a very rapid change of as much as $75^{\circ} \mathrm{F}$. in temperature, combined with the maximum difference in moisture content of the air. With water-cooled engines, therefore, it has been found necessary to put a thermometer in the circuit and fit the radiator with blinds operated by the pilot, and even with such accessories the maintenance of the water at a constant temperature has often been a matter of great difficulty, and has thrown a heavy responsibility upon the pilot. At the same time evaporation losses must be reduced to a minimum, as the amount of water lost on long journeys is an important feature, so much so that it is true to say that the Atlantic could not be flown to-day with any of the water-cooling systems that were deemed sufficient at the outbreak of war.

The intense vibration due to the conditions of high speed and lack of rigid support under which aero engines must work impose new and severe conditions mechanically on every part. 


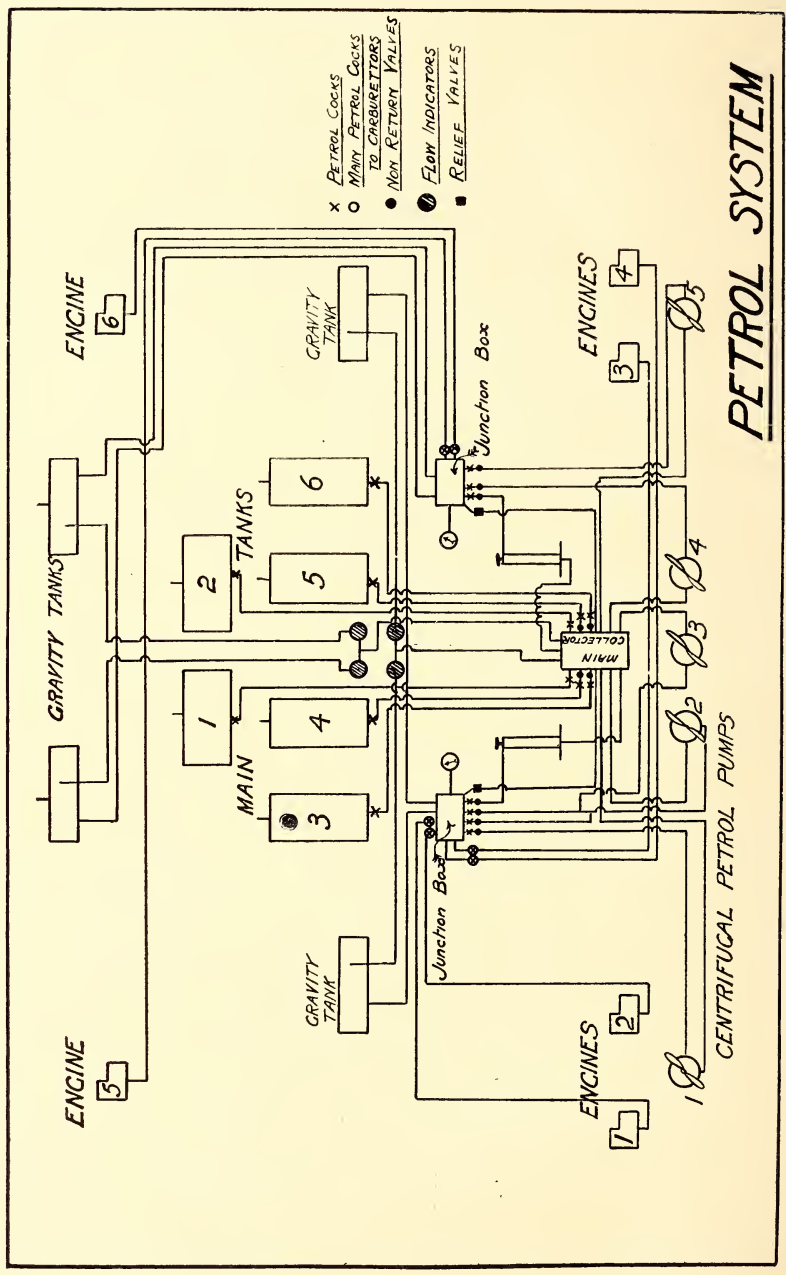


The violent and varying slip stream from the propeller also imposes a new problem as regards carburetter intake conditions, where again the seriousness of fire risk has to be taken into account and avoided. Probably no detail of the whole engine process has received more expert and prolonged attention than the ignition, and much of the increased reliability and efficiency of the modern engine undoubtedly results from this work.

The very severe centrifugal and inertia effects which are experienced in aerial fighting, coupled with the necessity under such conditions of immediate response to the throttle, have necessitated careful design of the petrol supply system to ensure a constant and adequate supply of fuel.

In addition, the length and ramifications of the fuel system have increased considerably with the growth in the size of machines and in the number of engines. Fig. 39 shows a typical lay-out of petrol system for a large modern multi-engined machine. The main tanks are numbered 1, 2, 3, 4, 5 and 6 and have a combined capacity of 1,800 gallons of petrol. These six tanks feed by gravity to the main collector which is situated in the engineer's cabin. In each of the pipes between the collector and tanks is fitted a non-return valve to obviate any possibility of the petrol running from the top tanks into the bottom as these six tanks are not all on the same level.

From this collecting box the petrol is lifted by five centrifugal pumps, which are shown below, into the junction boxes, which feed the engines. These centrifugal petrol pumps are driven by airscrews which are placed in the slip stream of the propellers in order that the petrol shall be pumped up whilst the machine is stationary. If these pumps should fail to act the petrol can still be lifted to the junction boxes by the hand pumps shown one on each side just above the collector.

The two distributors or junction boxes feed the engines; that on the left feeding the four bottom engines, whilst the other supplies the two top engines. As the petrol supplied to these distributors is more than that used by the engines, the extra amount passes up to four small gravity tanks which will be seen in the illustration and which are situated in the planes. These hold about 15 gallons each. As the excess of petrol continues the gravity tanks overflow through return pipes into the main collector. In these pipes flow indicators are fitted in order that the engineer may see that the system is properly working. After the main tanks are empty and no more petrol 
is supplied to the distributors the petrol flows from the \& ravity tanks into the junction boxes which ensure a further 60 gallons. The two junction boxes are fitted with indicators to show the pressure or head of petrol supplied. They are also fitted with relief valves discharging back into the collector. The collector is also fitted with a large filter, through which all the petrol passes on its way to the engine.

A great deal of progress has been achieved in the general arrangement of the engine and its cylinders so that the most effective use is made of all the material. With cylinders in line the deadweight loss per horse-power will rapidly decrease after the first cylinder, but after about four cylinders the economy to be gained by adding more cylinders practically ceases owing to the increased size of crankshaft and bearings required to resist torsion. This naturally leads to grouping the cylinders in two rows in $V$ form working on a common crankshaft with two connecting rods to each crank pin. Many such engines have been made with two rows of either four or six cylinders each. Further extension of this principle has enabled Messrs. Napier to produce a 12-cylinder engine of 450 horse-power with three rows of four cylinders (three connecting rods to each crank pin) and weighing only 1.86 lbs. per horse-power dry weight.

In addition to placing cylinders in line designers have from the earliest days of aero engines been attracted by the scheme for mounting all the cylinders radially around a common crank. By this arrangement the length of crankshaft and crankcase is, of course, reduced to a minimum, and there have been engines with three, five, six, seven, nine, ten, and fourteen cylinders in on€ or two planes. Of this type the Cosmos Co. have produced a 450 horse-power 9-cylinder air-cooled radial engine which weighs only $1.47 \mathrm{lbs}$. per horse-power or less than one-third the weights of similar type French engines of 1914-15.

Radial engines include those of the rotary air-cooled type, and progress in this type can be best indicated by taking the French 80 horse-power Gnome of 3.26 lbs. per brake horse-power, and comparing it with the British Bentley engine of 230 horsepower weighing only $2 \cdot 165 \mathrm{lbs}$. per horse-power, a reduction of about 30 per cent. in spite of the tremendous increase in the centrifugal load. With radial engines of large size, however, the increased head resistance is a serious objection, and it is not likely that this method of arrangement can be extended indefinitely as regards size. 
A saving in weight and great improvement in mechanical efficiency have been obtained by eliminating the valve tappet rods and substituting overhead cam shafts operating directly on the valves. Further economies have been effected by the employment of aluminium for the cylinders fitted with either steel or cast-iron liners. Pistons are now universally made of aluminium, and the gain in mechanical efficiency has been of even greater importance than the saving of weight. Hundreds of other details have also been the subject of most exhaustive study and improvement.

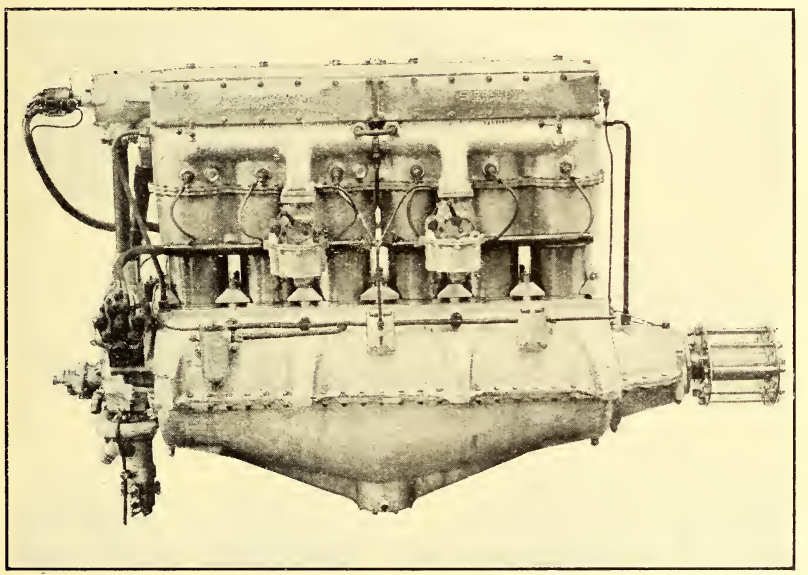

Fig. 40.-230 "Puma" (Siddeley).

The question naturally arises, how is it that such results have been obtained in such a short time and in face of so many difficulties with regard to labour and material. In the first place, the result has been obtained by the free use of money; the question of expense could naturally not be allowed to stand in the way of progress in this all important matter. Money has been spent on research, on steels and other materials, processes of manufacture, inspection organizations. etc., and the amount of scrapping of material and parts not up to standard has been on a scale that no commercial firm could adopt, and live. The greatest credit is due to the steel manufacturers for the manner in which they collaborated with the 
Government on the evolution of special steels and the preparation of standardized specifications.

The table on page 52 gives the principal particulars of some of the leading engines of to-day.

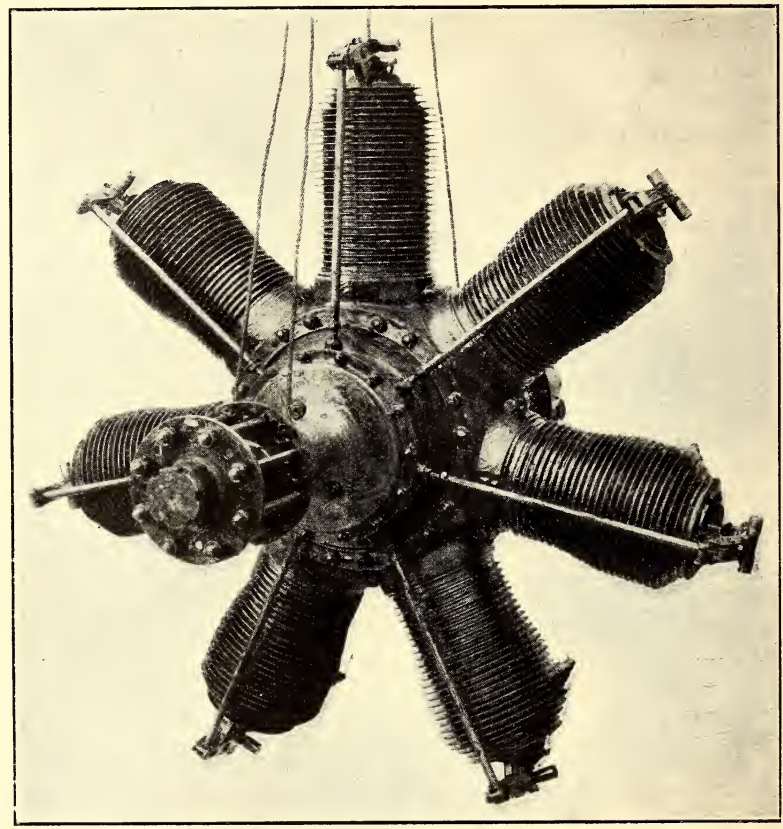

Fig. 41.-80 GNome.

Part IV.-Navigation and Meteorology.

Although great strides have been made during the last year in the development of scientific navigation the weather still remains the dominating factor in all flying operations.

During the war the whole of our aerial work was controlled by weather conditions, although in the later phases a vast amount of successful operations were carried out in weather which, 


\begin{tabular}{|c|c|c|c|c|c|c|c|c|}
\hline \multirow{2}{*}{ 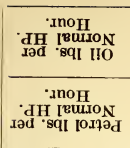 } & $\stackrel{\infty}{\stackrel{\infty}{\varphi}}$ & $\begin{array}{l}\text { co } \\
\text { ộ }\end{array}$ & 。ั & 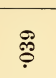 & ติ & 管 & สํำ & 网 \\
\hline & ஜृ & 象 & $\varphi$ & 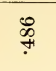 & 0 & 葛 & $\stackrel{9}{9}$ & 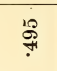 \\
\hline $\begin{array}{l}\dot{H} \\
\dot{\Xi} \\
\mathbf{\Xi} \\
\dot{\Delta} \\
\dot{g}\end{array}$ & 1 & 1 & 1 & 范 & ֻึ & $\underset{\substack{* \\
\dot{s}}}{*}$ & $\begin{array}{l}\stackrel{\infty}{\infty} \\
\dot{s} 1\end{array}$ & $\vec{i}$ \\
\hline 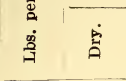 & $\stackrel{28}{\stackrel{9}{-1}}$ & $\stackrel{\infty}{\stackrel{\leftrightarrow}{-}}$ & $\begin{array}{c}\infty \\
\substack{0 \\
\vdots \\
i}\end{array}$ & $\stackrel{\circ}{\leftrightarrow}$ & $\begin{array}{l}\infty \\
: \\
i=1 \\
\vdots 1\end{array}$ & $\underset{\substack{0 \\
: 1}}{0}$ & 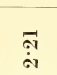 & $\stackrel{\infty}{\stackrel{\infty}{-}}$ \\
\hline 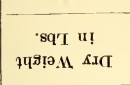 & $\stackrel{\infty}{a}$ & 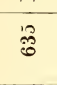 & $\stackrel{*}{*}$ & 高 & ๙ั & $\stackrel{9}{9}$ & 量 & $\stackrel{\infty}{\infty}$ \\
\hline 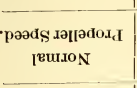 & 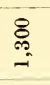 & $\stackrel{8}{:}$ & $\underset{8}{\stackrel{8}{+}}$ & $\stackrel{\overbrace = \mathscr{I}}{-}$ & $\stackrel{\mathscr{B}}{-\rightarrow}$ & 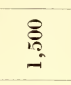 & $\overrightarrow{5}$ & 导 \\
\hline \multirow{2}{*}{ 产 } & 1 & 1 & 翟 & I & 惩境 & 1 & 茼 & 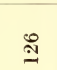 \\
\hline & \& & 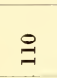 & $\stackrel{9}{=}$ & $\stackrel{9}{\exists}$ & : & : & 욬 & ฐ \\
\hline 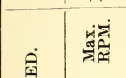 & $\stackrel{\circ}{\stackrel{\circ}{\circ}}$ & 唯 & $\stackrel{8}{\stackrel{9}{9}}$ & $\stackrel{8}{8}$ & $\stackrel{5}{-}$ & $\stackrel{8}{8}$ & $\stackrel{8}{8}$ & $\frac{8}{9 i}$ \\
\hline 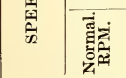 & 高 & $\stackrel{8}{:}$ & $\underset{8}{8}$ & $\underset{8}{8}$ & 离 & 总 & 总 & छ \\
\hline 娧 & 萿 & 煦 & $\stackrel{8}{\circ}$ & ริำ & 电 & 19 & 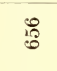 & $\stackrel{\infty}{\sharp}$ \\
\hline 害 & 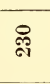 & คำ & $\sqrt{8}$ & 왹 & 品 & 品 & $\stackrel{9}{0}$ & 景 \\
\hline 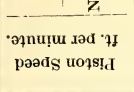 & 总 & 客 & 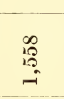 & 总 & 量 & 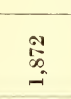 & 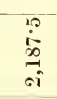 & 品 \\
\hline 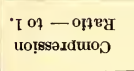 & 苚 & $\stackrel{9}{+}$ & is & 总 & is & 唱 & $\overrightarrow{\text { is }}$ & 量 \\
\hline $\mathrm{w} / \mathrm{ur} ә$ yons & $\stackrel{\infty}{\circledR}$ & 总 & $\stackrel{\S}{~}$ & $\stackrel{\circ}{\Im}$ & 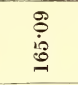 & $\stackrel{\S}{~}$ & 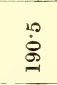 & $\overline{\dot{\hat{\theta}}}$ \\
\hline 'w/w anng & $\underset{f}{q}$ & 䊝 & $\stackrel{8}{3}$ & 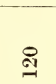 & 承 & 梁 & 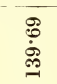 & 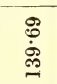 \\
\hline 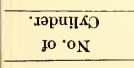 & $\infty$ & $\infty$ & 0 & $\infty$ & 의 & 워 & 이 & 이 \\
\hline 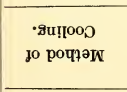 & $\begin{array}{l}\vdots \\
\vdots \\
4\end{array}$ & $\begin{array}{c}\vdots \\
\vdots \\
\end{array}$ & 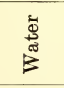 & $\stackrel{\tilde{\Phi}}{E}$ & $\stackrel{\mathscr{E}}{\mathscr{E}}$ & $\stackrel{\tilde{\$}}{\stackrel{\tilde{E}}{E}}$ & $\stackrel{\mathscr{E}}{\tilde{E}}$ & $\stackrel{\tilde{E}}{\mathscr{E}}$ \\
\hline 串 & 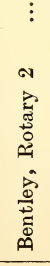 & 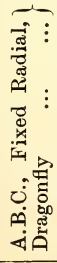 & 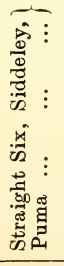 & 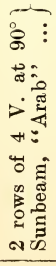 & 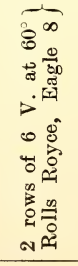 & 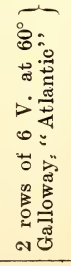 & 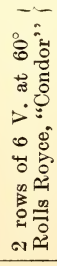 & 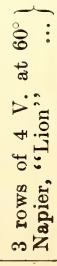 \\
\hline
\end{tabular}


before the war, would have been considered far too bad to allow of any flying at all. The problem of flying in anything like a thick fog or ground mist remains unsolved, and if flying in this country is to be a real commercial proposition much solid research in this direction will be necessary.

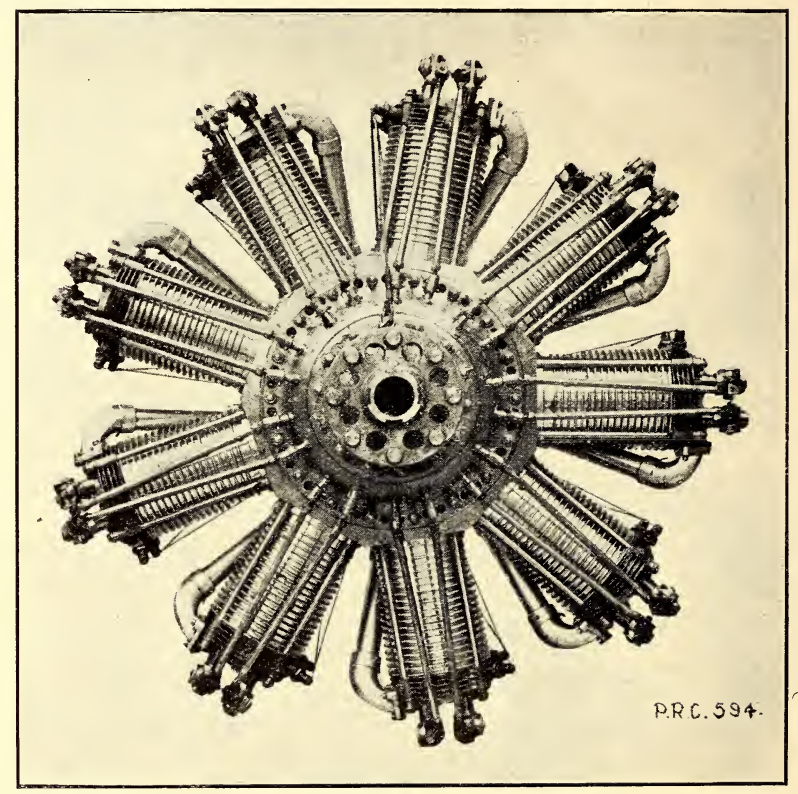

Fig. 42.-Bentley Rotary.

When the war started navigation was dependent mainly on map reading. Our machines were fitted with compasses, but these were of indifferent design, and could not be relied on unless the course could be frequently checked by a direct view of the ground below. The design of an aeroplane compass presents special problems, and the errors involved in using a compass of the type used on ships had not been realized before the war. These problems were successfully investigated by the late Keith Lucas, who evolved a satisfactory aeroplane compass. This compass and subsequent types based on its design were 
standardized. Even with the improved compass, navigation in unfavourable weather conditions still presents great difficulties.

The very great advantages, especially in long distance bombing operations, of being able to fly for considerable distances through clouds were clearly realized, and a special research was undertaken to make this a practical proposition. Excellent results were obtained, chiefly due to the introduction

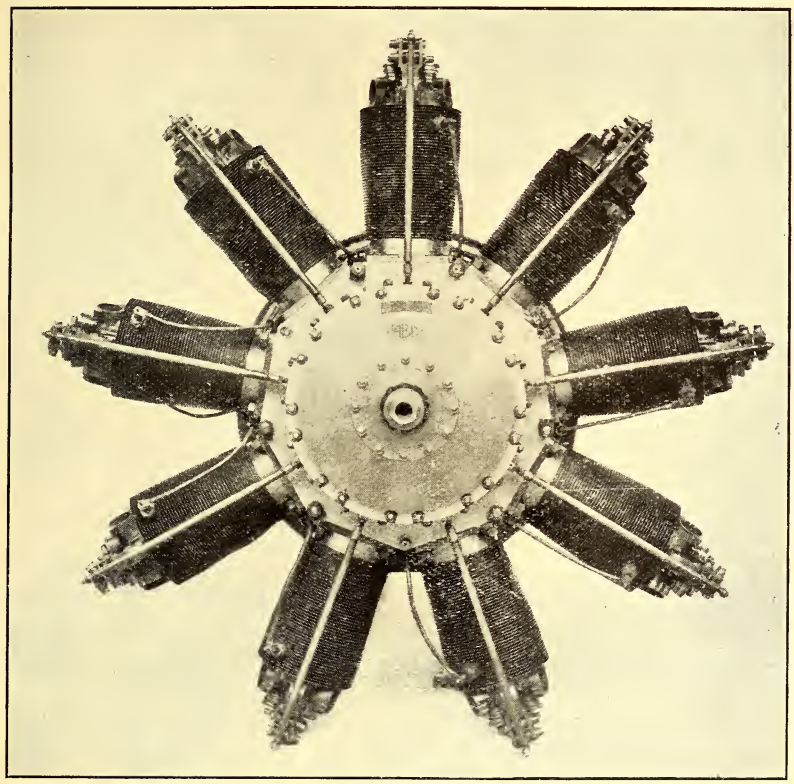

Fig. 43.-A.B.C. Dragonfly.

of an instrument called the Turn Indicator. When flying in a cloud or a fog-bank the pilot loses all sense of direction, but this instrument used in conjunction with the compass enables him to steer a straight course, even in these circumstances.

At the time of the signing of the Armistice we were training pilots in large numbers in the use of these instruments, and there is no doubt that the Germans would have had some unpleasant surprises a few months afterwards, when formations of bombing aeroplanes would have suddenly emerged from the clouds over 
their objectives when the inhabitants below might reasonably have considered themselves safe. Before any attempt could be made to attack them our aeroplanes would have been back in the clouds again and on their way home.

Navigation by dead reckoning is, of course, dependent on meteorological observations and for us, therefore, a good meteorological service was a sine qua non. It must be remembered that on the Western Front we had always this important disadvantage, that the prevailing wind was blowing from West to East, thus tending to drift our aeroplanes away from our lines and reduce their chances of getting back when in difficulty. In spite of this the vast majority of air fighting took place well on the German side of the lines, and, even allowing for the German raids over England, the amount of reconnaissance and bombing we carried out over German occupied territory was far greater than that attempted by them on our side of the line. Although, of course, the credit for this is mainly due to the magnificent spirit of our personnel, the effectiveness of our meteorological service had some effect in establishing our ascendancy.

A few words may be added about the use of Directional Wireless for navigation. The Germans used this method for directing their Zeppelins in the raid over England, but the system they used involved the sending out of frequent signals from the airship to be picked up by the German wireless stations. The latter would then send out signals to the airship indicating its exact position. This system had the great disadvantage that we also could pick up the airship's signals and thus locate its position. So we always knew where they were coming from, and arranged our defence accordingly. Our own system was for the aircraft to carry the directional coils, and by picking up signals from home stations, to locate its own position. Our apparatus was only perfected late in the war, but we counted on using it effectively in the projected raids over Berlin, to which I have already referred. With further research and development there are good prospects that Directional Wireless will be of the greatest value in the long distance navigation of commercial aircraft in the future.

Future Derelopments.-Any reference to the future of Aviation must necessarily be very brief and purely general in character. The rapid and quite abnormal growth in the technique and application of aircraft under the stress and 
artificial conditions of wartime must now give place to the more sober rate of development of peace-time.

Our peace-time Royal Air Force, as I visualize it, will become a relatively small organization of remarkable efficiency with the highest ideals and with the keenest esprit de corps. Its materiel should represent the last word in technical progress such as can only be achieved by considerable expenditure. Quality must be the keynote of its policy not only in materiel but also in personnel.

An outbreak of war must see us with the very best designs of engine and aircraft, tried and tested, and with a manufacturing nucleus on which war production may be readily expanded.

In regard to Civil Aviation, one is naturally unhappy at the necessity of adopting the prophetic role, but one factor is clear and definite. Our Government must accept the heritage of war experience, and by action, support, and sympathy, encourage and develop its translation into the new channels of peace requirements.

The more immediate problems of international and domestic aerial legislation have now been provisionally solved by the International Aerial Convention and by the Civil Aviation Act, and it is very gratifying that in both these directions Great Britain has taken the lead and shown the way.

In another direction much remains to be carried out quickly. Our great mercantile marine in all its technical perfection would avail but little without our harbours, docks, lighthouses, charts, and navigational instruments. We possess fleets of aircaft of reliability and of great performance possibility, but our navigational facilities are still almost non-existent, and herein lies one of the main fields of action of our new Department of Civil Aviation.

In all considerations for the future of Civil Aviation, the two qualities of outstanding merit appertainable to the new form of transport are speed and independence of action as against land transport requiring roads or rails. These constitute the only assets for any commercial future. Speed in transport is associated with high cost and speed will always command a high value. Early action should be taken in regard to a few main routes, especially in countries with equable weather conditions, and especially in new countries, backward in rail development. Two such main routes would be Egypt to India, and Egypt to South Africa. 


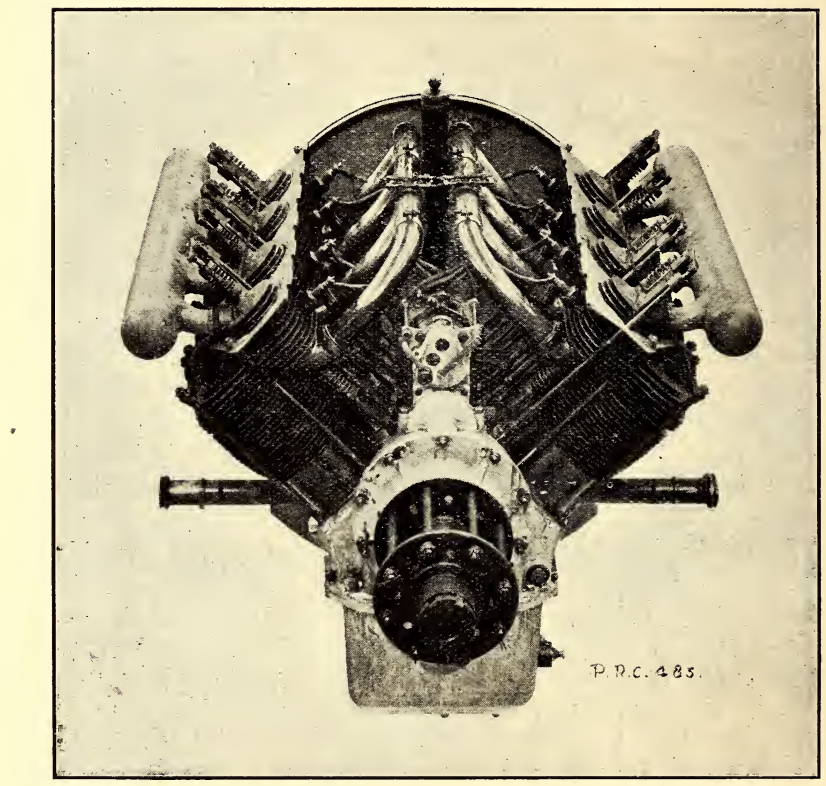

Fig. 44.-80 Renault. 
Another early development with immediate possibilities will be the use of large flying boats for inter-island and coastal traffic, for example, in the West Indies and New Zealand. The independence of the flying boat in regard to costly aerodromes, and its higher degree of safety in regard to landing places is a factor of great immediate importance. The Government and the large existing transport companies, shipowners, and railways might well collaborate in their early efforts, as the initial financial results will not be healthy enough for entirely new enterprises.

Another aspect must not be neglected-the encouragement of the sporting and popular use of aircraft-and it would appear essential that the great number of war aeroplanes surplus to Air Force needs should be distributed at a low price and as early as possible to the many small enterprises and even to individuals so that the community at large may have their present enthusiasm and interest in aviation maintained and encouraged.

In technical development of design our Air Ministry must spend money by development contracts, as private enterprise will not be able to support the developments for some considerable time. This applies in particular to engine development. Attention should also be devoted to improvements in landing carriages and landing problems, also the reduction in fire risks.

In conclusion, it would appear that the future rate of development will depend almost entirely on the permissible rate of expenditure and on the efficiency of the outlays.

I have to express my regret that lack of time has prevented this Paper from becoming more than a series of somewhat disconnected notes, but it is hoped that these may prove to record some of the more outstanding factors in one of the many great wonders of the World War.

I have to express by deep debt of gratitude to Lieut.-Col. Ogilvie and his partners, Messrs. Bristow, Pippard, Watts and Mayo for their invaluable assistance in the preparation of the Paper; also to General Seeley, Under Secretary of State for the Air, and finally to the different aeronautical contractors for permission to use the photographs of the different machines 


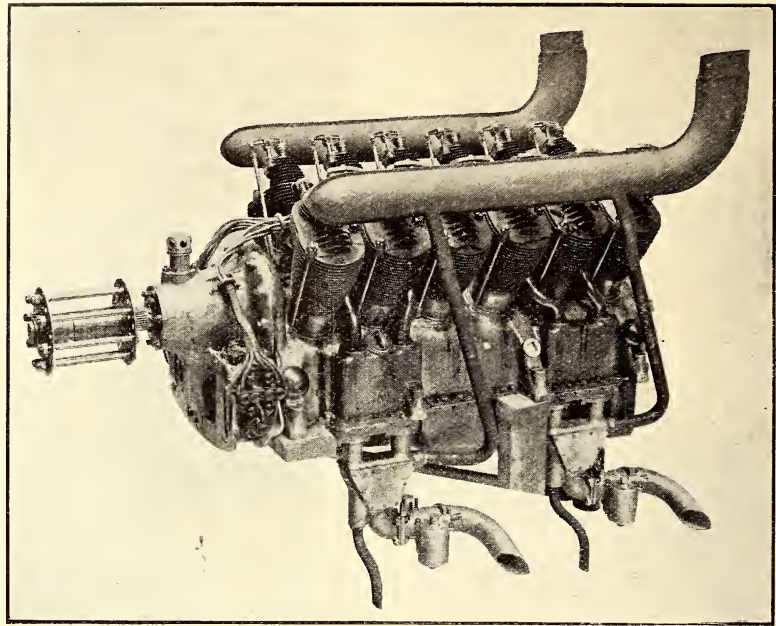

FIG 45. -140 R.A.F. 4A.

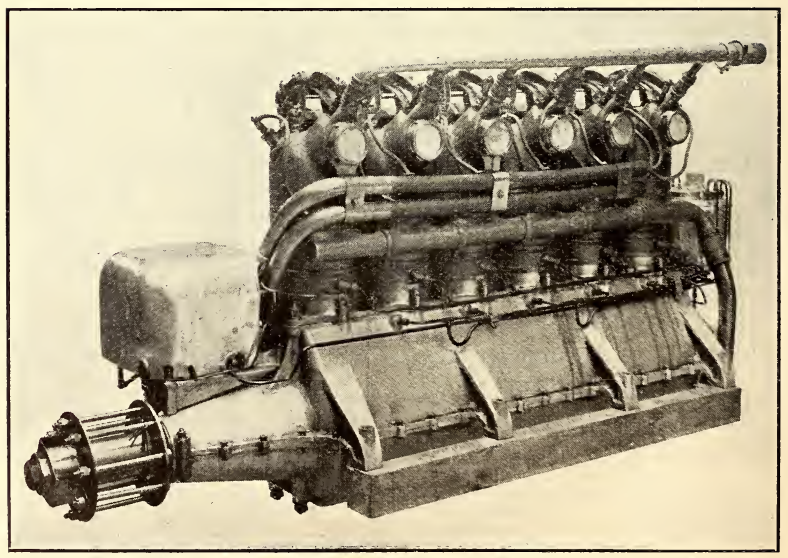

Fig. 46.-160 Beardmore. 


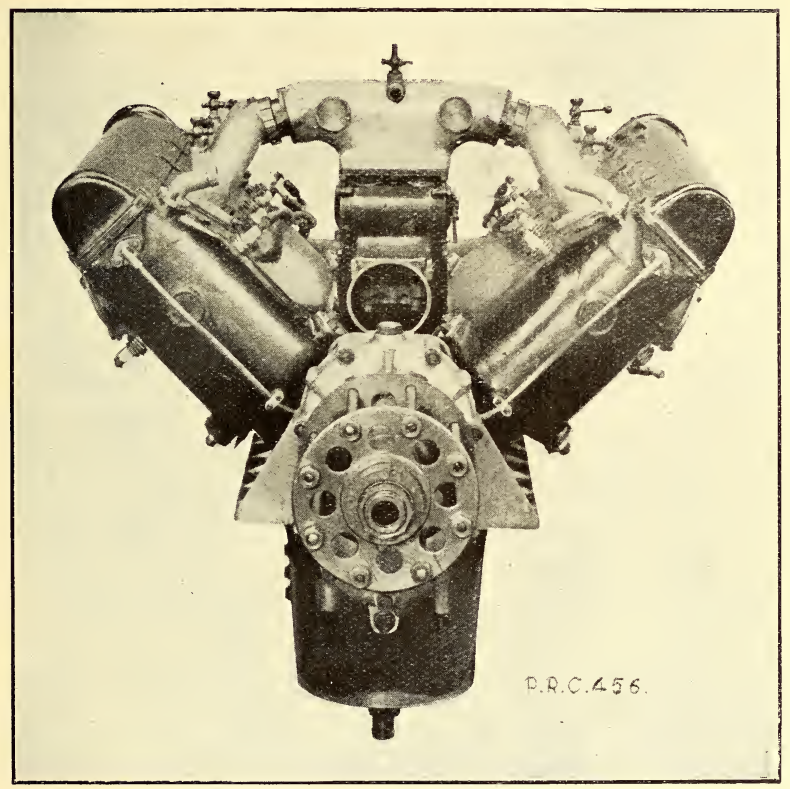

Fig. 4i.-Hispano-Suiza. 


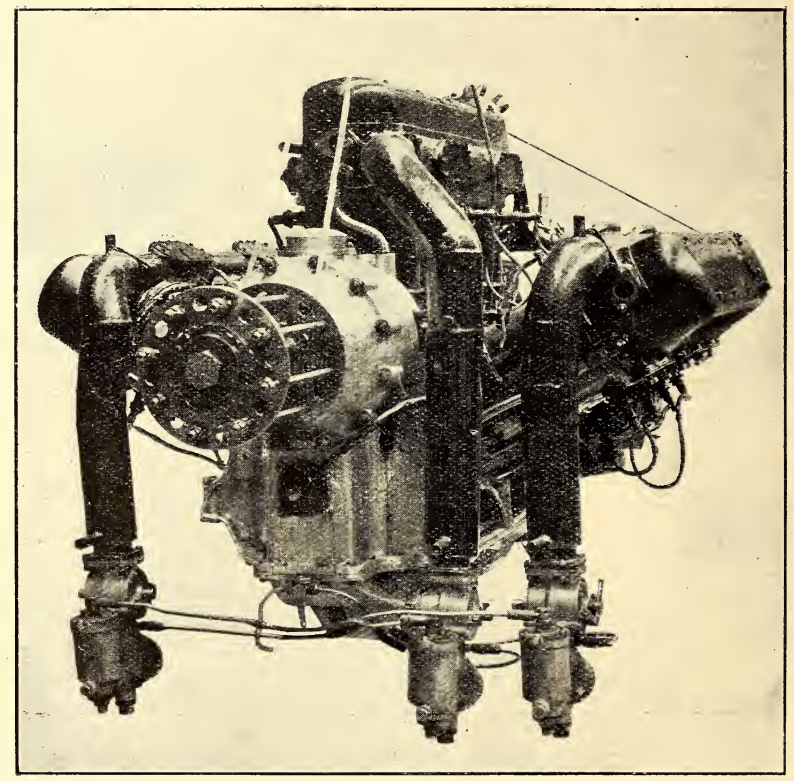

Fig. 48.-NAPier Lion. 


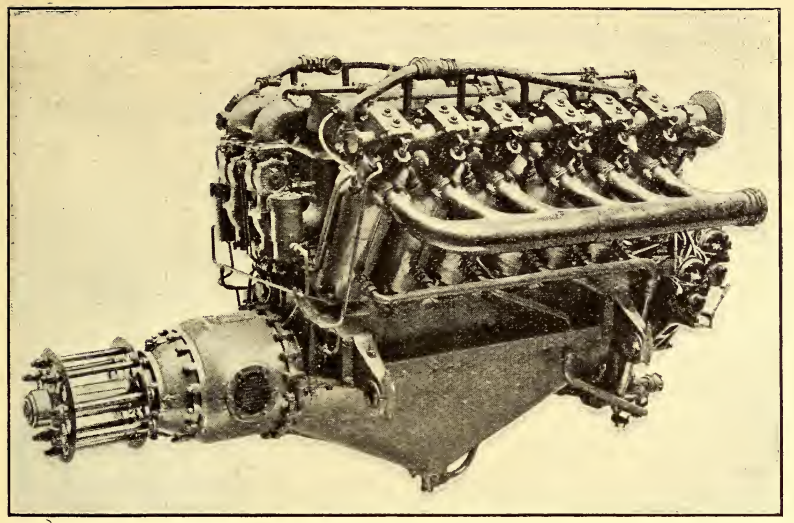

Fig. 49.-350 Rolls-Royce Eagle VIII.

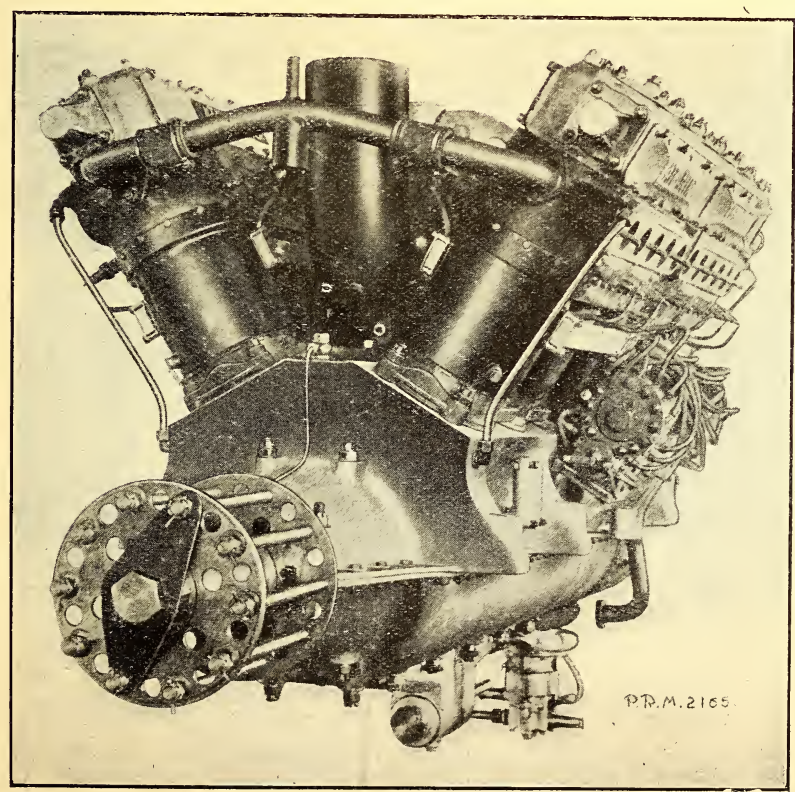

Fig. 50.-550 Galloway Atlantic. 


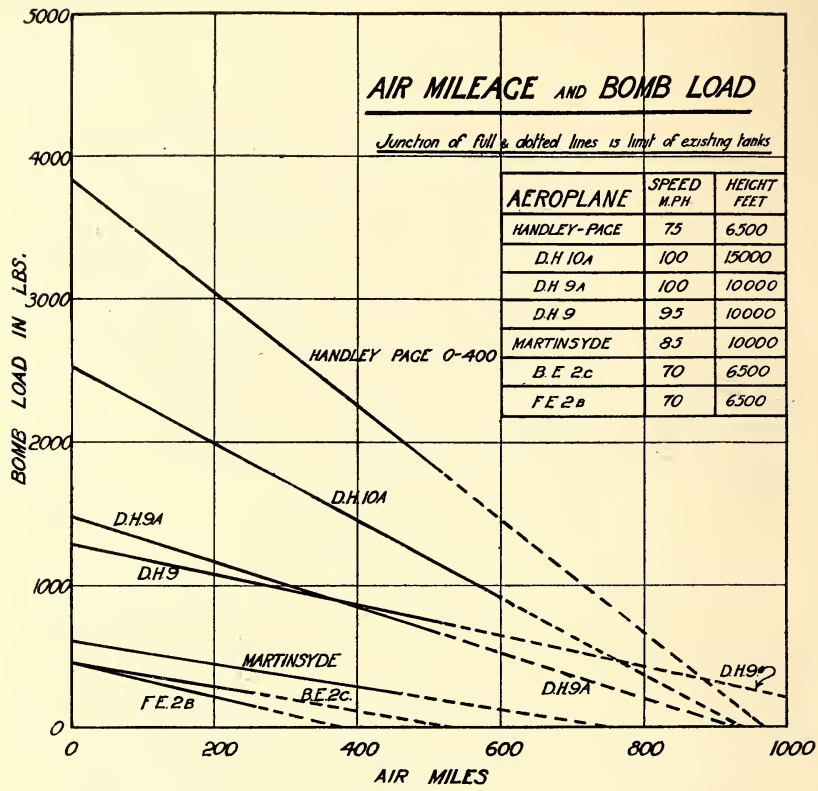

Fra. 51.

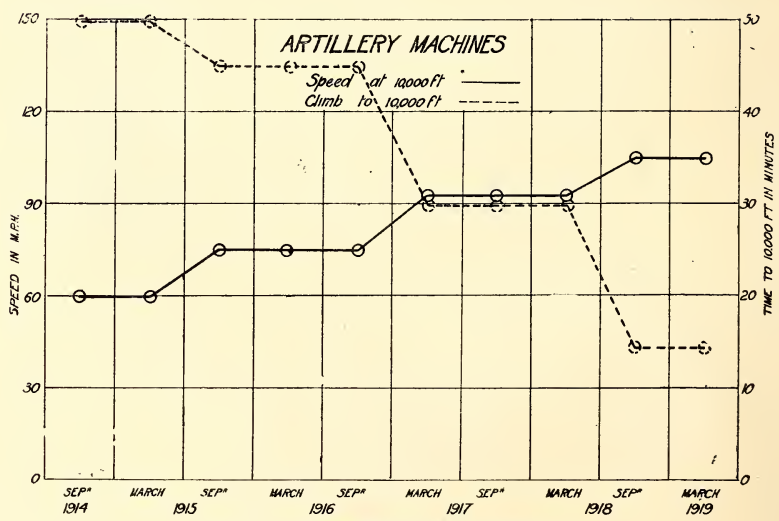

Fig. 52.--Performance Increaste. 


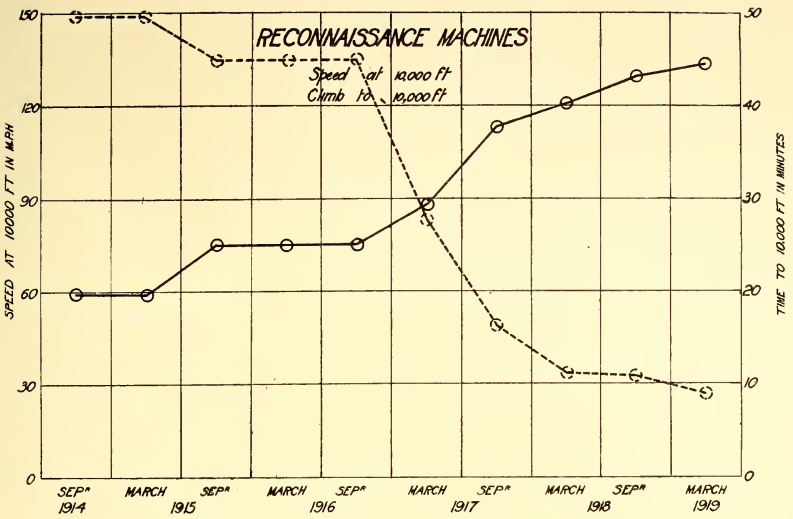

Fig. 53.-Performance Increase.

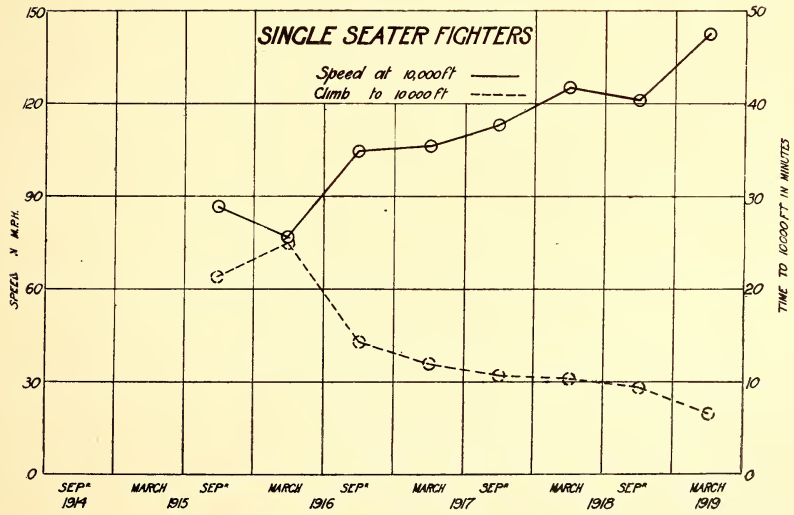

Fig. 54.-Performance Increase. 
66

SOME DEVELOPMENTS IN AIRCRAFT DESIGN

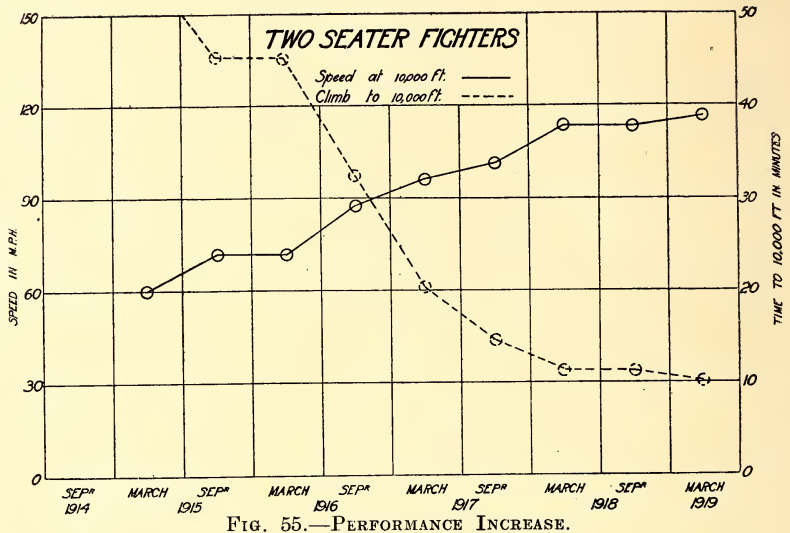

Fig. 55. -Performance InCRease.

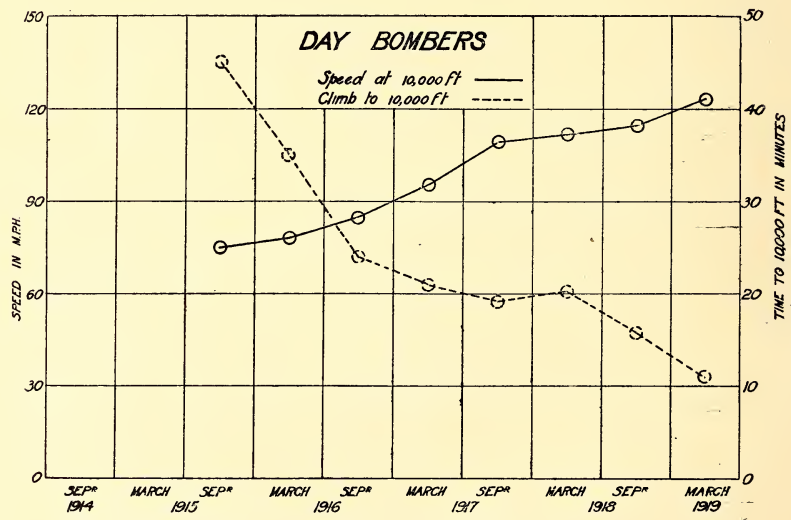

Fig. 56.-Performiance Increase. 


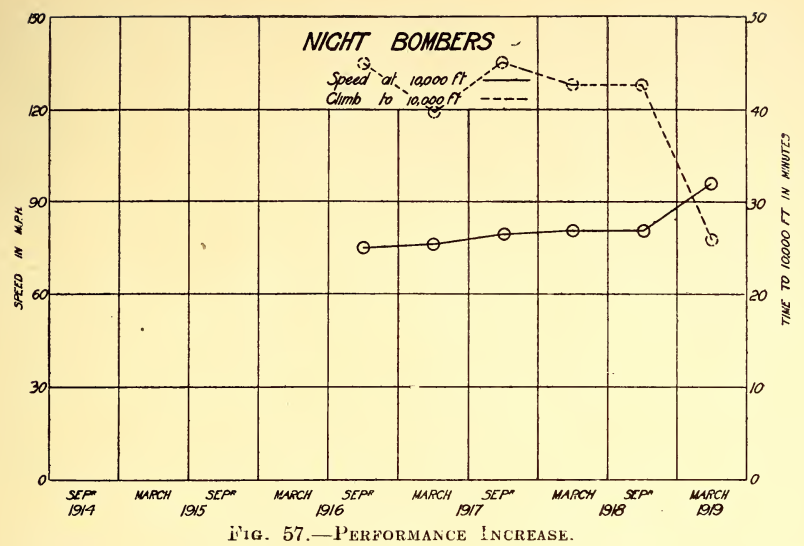

DISCUSSION.

The President, Mr. Edwin L. Orde, said that he took excep- The President. tion to the remarks made in the last paragraph but one, for the Paper was not simply a series of disconnected notes, but the most wonderfully concise and consistent history of the development of aircraft during the war that could possibly be compressed within the limits of such a Paper. The Institution was to be congratulated on that information, for the first time made public, being added to their Transactions.

He then called upon the Hon. Sir Charles A. Parsons.

The Hon. Sir Charles A. Parsons, Honorary Fellow, opened sir Chares A. the discussion. In the early days of the war Lord Derby had appointed a Committee to enquire into the efficiency of the Royal Aircraft Factory. The Committee had investigated the whole subject, and a great deal of valuable pioneer work had been done by the Factory; but the work had been too exclusive. That had not been entirely the fault of the Royal Aircraft Factory; insufficient money had been given to the trade generally to encourage the research and expansion necessary to meet the needs of the times. When the enquiry ended, Lord Weir was called in, and he filled the want which had been seen to exist. 
Sir Charles A Parsons

He had applied his well-known ability, which was never challenged in marine engineering work, to aircraft work, and to-day the result of his most brilliant work was seen.

A second enquiry in connexion with aircraft had taken place, and was sometimes known as the "Billing" enquiry, because it was concerned with the investigation of the charges made in Parliament by Mr. Pemberton Billing against the efficiency of the Royal Flying Corps. The most important recommendation made by the Committee was that the air service should be a united organization for both the Army and the Navy. Up to that time the Army and the Navy had been quite separate, and the combination had appeared to the Committee as a desirable measure for economic efficiency. One of Mr. Billing's charges had been that a certain pilot had been killed owing to the inherent weakness of a certain type of aeroplane which had collapsed in the air; he had deuied that it was possible to break a machine in the air, but Lord Weir had shown that it could be done.

It was well known that Langley was the first great pioneer of aviation. He had shown from the co-efficients of lift and drift, that it was possible to fly by steam power; in fact, from his work it became perfectly evident that flying by mechanical meaus was possible. The biggest bird that could fly was the eagle or the swan (about 10 lbs. in weight). With engines of steel and aluminium and rotary motion instead of bones, flesh and flapping, the size could be enormously increased.

Sir Charles was still of the same opinion as in 1912 when he had said that airships had a greater future than aeroplanes. He believed the airship would prove to be the most important aircraft of the future, provided that enough money were spent upon it. Millions of money would be required, and for ultimate success the work done on the airship would have to be well done. It would do all long-distance work, and if ever a Transatlantic service by air were established, it would be done by airships. The risks attendant upon craft heavier than air were far too great.

Engineers would all appreciate the great advance which had been made in aircraft engines, and the consummate skill evinced in their design and manufacture. In marine engineering not very long ago very light reciprocating engines for torpedo boats and destroyers had been needed, and the late $\mathbf{M r}$. Frank Marshall on the Tyne had been foremost in applying such engines to cruisers. Bearing this somewhat parallel case in 
mind, marine engineers could form a fair conception of the very sir charles $\mathrm{A}$ great progress which had been made in the construction of aeroplane engines. They also realized the great difficulties and the great expenditure Lord Weir had mentioned as being necessary if good pioneer work was to be done in the future. $\mathrm{He}$ thanked Lord Weir for his admirable Paper.

Sir Dugald ClerK said that Lord Weir had given an sir Dugald clerk excellent account of the activities which had produced the present aeroplanes and engines, but he did not think he had mentioned the work of the Advisory Commitee on Aeronautics. It was a scientific committee formed in 1909 by Mr. Asquith, the then Prime Minister, and the Chairman was the late Lord Rayleigh-one of the greatest of British scientific men. Under Lord Rayleigh that Committee had done excellent work. It had controlled the experiments at the Royal Aircraft Factory, started about 1909 , so that before the war, although Britain was in a bad position with regard to the number of aeroplanes and engines in actual use, the science had been fairly fully considered, and experiments and work on stability developed. The Advisory Committee on Aeronautics had dealt with problems of construction, problems of stability, and all the numerous problems to which Lord Weir had alluded in his Paper, some of which were of a most interesting nature. The question of the compass, for instance, and the production of the Keith-Lucas compass, had been dealt with. It had been found that in any ordinary compass constructed for ship work, under the ordinary conditions of flying, the compass needle, instead of setting in one definite direction, had a nasty trick of turning right round. KeithLucas had studied that, and found the means of making a more perfect compass. It had been still found, however, that under some circumstances, if the aeroplane happened to be in a fog, the pilot could not tell whether he was flying straight or not, the compass being so much affected by the curve which the aeroplane was taking in the air. That had been solved by the turn indicator, which determined whether the aeroplane was flying straight or turning by detecting differences of air pressure at certain extreme points. If those pressures were not the same, then the turn indicator, which had been produced under Sir Horace Darwin, proved very useful in the way Lord Weir had stated.

Sir Dugald's connexion with the question had begun definitely 
Sir Dugald Clerk in 1916, when he was asked to join the Advisory Committee on Aeronautics to give special attention to the engines. When he joined the Committee he had at once seen that the conditions imposed upon makers on the scientific side were too rigid, and that they ought to have more latitude. He became Chairman of the Engine Sub-Committee to deal with aeroplane engines. The duty of this Committee was to visit the different works of the country to ascertain the difficulties with which the makers had then to contend. All the engine designers of the country were invited to go and see the Committee in connexion with the design of engines. Those discussions had begun in 1916, and had lasted up to the present time.

Lord Weir had made a very important point when he spoke of the inability to take the fullest advantage of standardization. An outcry had been made because Britain did not standardize aeroplane engines. Sir Dugald had been questioned by some of his M.P. friends, who said, "Why don't you standardize the engines?" To these he had replied, "We don't standardize because we want to beat the Germans." The Germans had standardized early in the war. It was an excellent thing to standardize when it was known what was to be standardized: otherwise, however, standardization was of no use.

The Committee had had to settle what should be done with regard to the wonderful high flying. That was one of the questions which had to be determined by the weight ratio between the aeroplane and the engine. When the proportion of weight to propelling power was large, there was great difficulty so far as " stunting" was concerned. It accordingly became necessary to design engines that would have a " ceiling," as the flying men called it, much higher than anything yet attempted. The difficulties were these: When flying near the ground the pressure of the atmosphere was, roughly, $147 \mathrm{lbs}$. per sq. inch. At a practicable height the atmospheric density diminished to one half. The total indicated power was directly proportioned to the atmospheric pressure. So if one went up so high that the atmospheric pressure was reduced to one half, the indicated power of the engines would also be reduced in the same measure; the power diminishing as one ascended. There were three methods by which the Committee had attempted to overcome the difficulty of loss of power with heioht. The first method was attempted early in the day by Colonel O'Gorman. $\mathrm{He}$ attached to his engine a high-speed fan of about 30,000 revolutions per minute, and as the engine rose the fan was set 
in motion. He had obtained at that time the assistance of Sir Sir Dugald Cerk Charles Parsons. By so increasing the pressure of the internal atmosphere within the cylinder, he found that they got increased indicated power proportionately for very great changes in level. Colonel O'Gorman's method had been fairly successful, although it had not appeared in actual work. Several modifications of it had since appeared.

A second method had been to supply what was called supercompression. Sir Dugald had been the first to use that method in connexion with land engines fifteen years ago. The mean pressure could be greatly increased by super-compression. By this method an additional charge of air was compressed. Fxperimental engines were built for the purpose.

The third method was the one which Sir Dugald most favoured, and that was to build the engine of such proportions that it would be inadvisable to keep it running very long at more than level pressures, the margin of safety being too low. Such an engine would give a high power at that level, but the throttle would be nearly closed. As the aeroplane rose, the throttle opened, and as the machine flew higher and higher a pressure in the cylinder was obtained whirh was approximately the same as that at the beginning of the flight at the ground level. The one type of engine which the Committee had encouraged was the "Lion," to which reference was made in Tord Weir's Paper. The "Lion" engine was giving excellent results. It was a light engine considering power obtained per unit weight, and it had gone as high as 30,000 feet in the air simply by the expedient of having large cylinders. The design was a matter of rather delicate proportioning. The engine had not to be broken up, and yet a factor of safety at atmospheric pressure lower than the usual value was necessary.

There were many other problems to face. The amount of data which the Committee had accumulated could hardly be believed. At the ordinary monthly meetings of the Advisory Committee for Aeronautics there were seldom less than thirty scientific papers; and at the Engine Sub-Committee, dealing with engines only, in the three years over 250 senarate scientific papers had been considered. These dealt with every possible phase of the subject from engine construction, compression, and the methods of increasing thermal efficiency, to magneto construction, and other details.

In dealing with proneller hosses. it had been verv soon found whon the S.E. 5 machine went into the air, that in some cases 
Sir Dugald Clerk in a few minutes the propelling boss became so hot that it sometimes ignited. That was due to the fact that the same proportions had been used as for rotary cylinder engines. On the other engines there was no fly-wheel effect, and if the power was raised to over 300 the bosses would not stand the varying torque. That was another of the smaller problems which had come before the Committee. Occasionally the shaft driving through the sleeve of the boss created longitudinal vibration. That had been put right by clearing away certain spaces, while another remedy had been that of making larger bosses. Many other problems were brought before the Committee, and its members had always worked most happily together under Lord Weir, whom Sir Dugald thanked again for his excellent Paper.

Lieut.-Colonel OgiLvie said that he wished to put before the meeting the great advantage of light-weight engines, not only from the point of view of aircraft, but also from that of the many other purposes for which internal combustion engines were suitable. The largest engines at the end of the war were of about 600 horse-power, and weighed only about $2 \mathrm{lbs}$. per horsepower. Supposing a man of the calibre of Mr. Royce were asked to design a motor wherein he was allowed to use $4 \mathrm{lbs}$. per horsepower, providing 100 per cent. reliability were obtained, there was little doubt that he would be able to do it. That would be something very valuable. The disadvantages were that a very high degree of workmanship was required, and also very good materials. He thought he was right in saying, however, that the cost of materials of improved quality was steadily going down, and by standardizing and improving production methods, good workmanship could be obtained fairly cheaply. Therefore it was going to become less expensive to make high grade engines of the quality such as he had suggested. When these reductions in cost of production had been secured the possibility of much bigger developments in many other directions appeared--in the replacing of steam engines in yachts, in greatly increasing the efficiency of engines in motor cars, and in many other directions. As regards motor cars, modifications of the light air-cooled engines, developed at the end of the war, were already being utilized in motor cars, and he thought that ultimately it would be found that there would be cars very much lighter and relatively cheaper than formerly.

Another point which he wished to make was that great advances had been effected in regard to the avoidance of 
accidents. It was at this stage of the greatest importance for the Lieut-Col ogilvie development of commercial aviation that every possible precaution should be taken to avoid accidents. He thought that point should be driven home with the greatest possible force; further, it was necessary to publish for the benefit of designers generally all the results of past accidents. During the war there had been an immense accumulation of data concerning accidents, which data had been of the first importance in assisting designers and Government departments to keep on the right road. That data should be published, and all the data in connexion with future accidents should be given with the greatest freedom. Such information was very much required by designers.

With regard to the point about breaking a machine in the air, it would be quite possible to build a machine which could not be broken in the air; in fact almost any kind of machine could be built so that it could not be broken, but the disadvantage would be that it would have to be made of such air resistance that it would not be capable of a high speed.

He believed that a great deal in the future depended upon the development of high-powered, cheap, reliable engines. There was no serious difficulty now in the design of large machines, particularly large seaplanes which would require three, or four, or five thousand horse-power in one unit. That was probably not outside the range of an internal combustion encine. Perhaps although he spoke diffidently on the subject-it would be possible to build cylinders giving 400 horse-nower without exceeding an engine-weight of 5 or 6 lbs. per horse-power. Such developments would be required in the future.

Brigadier-General Groves remarked that the earlier part of Brig-Gen. Groves the discussion had been confined to the material aspects of design; he thought that some reference to the development of the man who flew the machine might be of interest, because, after all, he was the chief consideration in the long run. In connexion with factors of safety and the design of machines which it was absolutely impossible for a pilot to break in the air, he thought that such designs were hardly necessary. The weight penalty was so great and, furthermore, pilots were developing a form of instinct which prevented them breaking machines in the air. As for those who did not possess that instinct, by a process of elimination, the problem solver itself. The same thing happened in marine work, where seamen had developed much the same kind of instinct in handling small craft in heavy 
Brig-Gen.Groves weather, knowing instinctively and by experience how long they could carry on before their spars were carried away.

Royal Aircraft Factory Experiments.-He did not wish to refer particularly to the scientific demonstration of stresses carried out by the Royal Aircraft Factory, mentioned in Lord Weir's Paper, but he thought it not without interest to give a little insight into that investigation. There was a certain French pilot called Navarre, who had invented a spinning nose-dive-a pretty evolution which looked terribly alarming. The first man who found out how to get out of the spin without reaching the ground discovered something very valuable, as it had formerly been thought that if one got into a spinning nose-dive the result must be disastrous. The Royal Aircraft Factory had been asked to investigate this evolution, and after wind channel experiments Professor Lindemann and others fitted certain machines with the necessary apparatus, put themselves into the required attitude-alarming for those not accustomed to flying, and sufficiently alarming even for those who were so-and observed the results. No praise could be too high for men of that type.

Load Factors.-General Groves disagreed with the load factors allowed in Lord Weir's Paper for ordinary flying. Pilots had to take the weather as they found it, and for small machines the factors of safety adopted would have to correspond to those developed in fighting machines. In the larger machines which flew much more steadily, when they tended to heel over and so forth, the pilot could feel what was coming, and had time to get back to a normal attitude. Sometimes, however, they found themselves driving a small powerful-engined machine through an atmospheric disturbance like the centre of a thunderstorm, which was worse than an ordinary gale. What with atmospheric discharges and the wind changes in direction and velocity, the machine was suddenly hurled about, and they got into all kinds of vertical attitudes. The nilot might be partially blinded by heavy rain and unable to see the instruments, which was in itself a reason for allowing a large factor of safety. The sensations of flying under such conditions felt very familiar to the seaman. It was like driving through a heavy sea in a torpedo boat, or like being in a small sailing vessel when one had to carry on with a lee-shore, and consequently felt almost helpless. Under such circumstances, it was a trial not only of mechanical stresses, but of the brain and nerve of the pilots in contest with the elements. It was satisfactory to feel that the machines would 
come into the hands of a race of men who were definitely Brig-Gen. Groves developing the flying instinct.

Flying Boats.-C'here were some interesting remarks in the Paper on the percentage of structural weight to the total weight, especially the statement that the percentages were approximately constant in nearly all sizes and types of aeroplane. In other words, large aeroplanes did not carry more weight proportionately than the small ones, and in this, of course, the aeroplane differed very much from the airship. Possibly the most interesting point was that the weight of a flying boat's hull was not greater than the fuselage and undercarriage of a large aeroplane. General Groves had met men within the last few months who would have laughed that opinion to scorn, or would have said that such a hull would not stand the stresses and shocks from the waves. Nevertheless, such hulls did stand a lot of stress, and water was much harder than the hardest of steel if hit in a certain way. In fact, the hulls were remarkably strong and elastic. The flying boat, he believed, had a great future. During the war it had been necessary to do a great deal of work by aeroplanes which should have been done by seaplanes; but at that time these were not in existence in sufficient quantities. When the flying boat or seaplane was ftying over the land, one naturally felt that all was lost if the engines failed, but the circumstances were different in the case of an aeroplane engine failure over the sea. In the latter event the aeroplane was almost bound to be lost, but on favourable ground a flying boat could be landed without serious damage. In most cases, of course, it could not proceed on its flight, but had to be dismantled and taken home. Although he could not vouch for the story, he had been told that one flying boat, which had landed in Yorkshire in a fog, had actually continued its journey as the erew succeeded in bringing the machine to some water, from which it was able to rise. Flying boats had been known to land in deserts, but he had never heard of any case where pilots or passengers had been killed through a flying boat making a forced landing on the ground.

Commercial Flying.-General Groves then dealt with the possibilities of commercial flying. The British Empire had developed largely along the lines of sea communication; there were, furthermore, eight rivers in the world from 3,000 to 4,000 miles in length, which ran through the heart of the world's markets, or, at least, potential markets. These rivers were 2, 3, 4 and 5 miles broad, and had ample depth for flying boats. There 
13rig-Gien. Groves was thus a great opening inere tor developing trade, and riying boats or seapranes had a grear aavantage in unueveropeu countries, because one did not have to biy land for aerodromes and fence it and guard li. They couid land upon a river, and they did not have the dificulty of rough seas. I he possibility was being consideled of sending one of the large tiying boats on a progressive trial voyage to Lgypt, up the Nile, then on to the Great Lakes, to the Zambesi, and so on, perhaps even to the Cape. If it were still going it would come back again, but if it only got over the first three or four stages of such an expedition the expenditure of a flying boat would be justified by the information gained. The construction of a large tiying boat hull lent itself naturally to long range communication. 'The crew could walk about in it, could communicate without telephones or voice pipes, and could have bunks for sleeping in. As the larger boats remained louger out of their sheds, more would be learned about the weathering properties of dopes and fabrics; but they had already remained out and kept in flying condition for four months at a time in temperate climates. There were places where, by taking little hops over land, it would be possible to complete long lines of communication. Rivers provided a waterway nearly across India, and it might be possible to join up with the Congo, through Egypt, and so forth. Air communication then would tend largely to follow the great rivers, and for longer distances there was the airship itself.

Airship Possibilities.-At this stage General Groves was handed a message which had been received by telephone stating that the R. 34 had left New York, and giving her exact position after the first three hours of her return journey to the United Kingdom. The General went on to explain that the arrangements for the trip depended upon the co-operation of the Admiralty, who had sent out two large battle cruisers, not so much to rescue the ship as to give meteorological information. The airship, he was inclined to think, was the best aircraft for any non-stop journeys of over 2,000 miles, but he favoured the large aeroplane for shorter distances. The airship gained in efficiency the larger it became, in which respect it was unlike the aeroplane. When airship dimensions reached about eight million cubic feet (about three or four times the capacity of R. 34) the larger reserve of disposable lift would make steel construction possible. An eight million cubic feet ship would be able to fly perhaps 15,000 miles in still air. This was also one of the developments of the future, and he anticipated that the large traffic concerns, 
with all their organization and facilities for maintaining Brig Gen. Groves stations, would take up these airships in a very few years. It would be found that aviation would not be the rival, but a very useful help in developing the main lines of mercantile traffic.

\section{CORRESPONDENCE.}

Contributions from Constructors.

Mr. Oswald SHoR'T regretted that the seaplane side of Mr.oswald sbort aviation had been entirely ignored in the Haper. During the war the land side had naturaily been more in evidence, but the work carried out by seaplanes had not only been considerable, but of great value. Apart from purely naval reconnaissance, an enormous amount of which had been caried oul, the whole of the seas within a consideiabie number of wiles of the british coast-this represented only one theatre of war-had been contimuously and closely patrolled by seaplanes-irequenily under very adverse conditions - with the object of locating and destroying enemy submarines. It had been acknowledged on all sides that these patrols were to a large extent instrumental in successfully fighting the submarine menace.

One of the most important developments in naval warfare was the torpedo-carrying machine, designed and construcied by Messrs. Short Bros. This type had been used with success in the Eastern theatre of war, the first ship to be torpedoed from the air being a Turkish transport. For a long time nothing more had been done with this valuable weapon, but late in 1917 its importance had been recognized by the authorities, and Messrs. Short Bros. had been requested to design a new machine to carry a torpedo of $1,800 \mathrm{lbs}$. This machine was built and tested, and large orders were just about to be placed, when the armistice was declared. It was admitted in naval circles that more attention should have been concentrated on this form of warfare than was officially given.

As the Managing Director of the largest seaplane constructing firm in the world, and designer of the machines which were adopted as standard by the British Government, Mr. Short felt that the important work done by seaplanes had been rather kept in the background, and he briefly expressed his views on the bearing of seaplanes on the future of commercial aviation.

It would be realized that for a small congested country such as Great Britain, in which travelling facilities were so complete, 
Mr oswald Short the use of the seaplane would be greatly restricted from a commercial point of view. The competing methods of transport, such as railways and motor services, could be run so efficiently as to negative or reduce to a small margin the saving of time which could be made by aerial travel. On the other hand, Great Britain was an island, and to follow any of the main commercial lines necessitated a sea crossing. It was thought highly improbable that in the future aerial passenger traffic could be allowed to make these crossings in anything but seaplanes.

$\mathrm{Mr}$. Short thought that this point should be seriously taken up, because the first consideration in commercial aviation was safety. The first step to be taken to attain safety was to eliminate all chances of accident, and it was obviously inconsistent to transport passengers across the sea in machines which were not designed to land on and get off water.

These remarks showed the important bearing that seaplanes would have on the future of aviation. In the opinion of many, aeroplanes had already reached their maximum dimensions, the limiting factors being the provision of large enough landing grounds, and the design of the landing chassis. The seaplane would not be affected by either of these two limitations, and as far as Mr. Short could see there was no reason why this type of aircraft should not be built up to considerably greater dimensions and carrying capacity.

Mr. T. O. M. Sopwith said that there was one matter which had apparently not been referred to in the Paper, which was that at the time Lord Weir took over the direction of aircraft production, the designing firms were in a somewhat chaotic state, there being no one in authority to whom constructors could go and get an indication of what was expected of them in the way of design and production to maintain the two air services. Shortly after Lord Weir took up his duties, all that had been changed; the heads of various firms were called in and freely consulted as to what the capabilities of their establishments were, and as to how these could be best augmented. Keenness and enterprise were carefully fostered, and constructive criticism substituted for the destructive eriticism with which makers had in the past been contending. They were told that the door of Lord Weir's room was always open to them, and they did not fail to make good use of that invitation. No difficulty had been too small for his attention if it was in any way clogging the machinery 
of progress, and Mr. Sopwith had no hesitation in saying that it Mr. T. o. M. was Lord Weir's sympathetic understanding and his wonderful organizing abilities which had placed the British aircraft industry in the truly wonderful position which it held at the cessation of hostilities. Mr. Sopwith only hoped that his influence would remain, and that the splendid supremacy to which he had brought the British aircraft industry would never be lost through indifference to the need for encouragement and support from the Government, on which it would be so dependent for the next few years.

The Supermarine Aviation Works, Limiten, contributed The Supermarine a few notes on the development of seaplanes (flying boats), the Limited construction of these being the class of : vork upon which they were chiefly engaged. Their object, as builders, was not merely to make an aeroplane float, but to construct seaworthy hulls which would fly. Touching on the question of commercial aeronautics, it was obvious that if a flying boat could give a similar performance to an aeroplane, the latter type of machine would never be used across water, and it was also obvious that, for a country in an insular position like Great Britain, the question of using commercial flying boats, as an auxiliary to the merchant fleet, was of vital importance. It was now quite possible to make a flying boat which could get off or alight in practically any weather, and whose aerodynamic qualities were quite as good as those of any land machine. In some respects a flving boat was more stable than an aeroplane. The placing of the weight below the planes (i.e., in the hull) gave more lateral stability, while, with a pair of good wing floats, the chances of a bad landing were nil.

Coming to the question of construction, the structure of seaplanes generally had to be more robust than the average land machine owing to the deteriorating effect of sea water on all metal parts and the chances of sea water breaking over the wings in bad weather. This meant increase in weight with a relative reduction in performance. High engine thrust above the centre of gravity also caused a certain amount of loss in aerodynamical efficiency, due to correcting tendencies which had to be made in the tail structure.

The Company gave the following figures showing the performance of one or two types of flying boat, as designed and constructed by them :- 
The Supermarine Aviation Works Limited

\begin{tabular}{|c|c|c|c|}
\hline Type. & Load & Speed. & $\begin{array}{l}\text { Climb to } \\
10,000 \text { feet }\end{array}$ \\
\hline $\begin{array}{c}2 \text { Seater. Reconnaissance } \\
\text { Flying Boat (1917). }\end{array}$ & $\begin{array}{c}4 \frac{1}{2} \text { hours fuel, gun and } \\
\text { ammunition. Wire- } \\
\text { less signalling gear. }\end{array}$ & 100 M.P.H. & $25 \mathrm{~min}$. \\
\hline $\begin{array}{c}\text { Single Sexter Fighter } \\
\text { Flying Boat (1918). }\end{array}$ & $\begin{array}{l}3 \text { hours fuel, gun and } \\
\text { ammunition. Sig- } \\
\text { nalling gear. }\end{array}$ & 117 M.P.H. & $12 \mathrm{~min}$. \\
\hline $\begin{array}{c}\text { Single Seater Fighter } \\
\text { Flying Boat (1919). }\end{array}$ & $\begin{array}{l}2 \text { hours fuel, gun and } \\
\text { ammunition. Sig- } \\
\text { nalling gear. }\end{array}$ & 150 M.P.H. & $5^{\frac{1}{2}} \mathrm{~min}$. \\
\hline
\end{tabular}

\section{AUTHOR'S REPLY.}

Lold WEIR, in reply, thanked the members of the Institution for their appreciation of his Paper, and, at the same time, expressed his indebtedness to those who had made such valuable contributions to the discussion.

With regard to the kind personal references, any effort which he had made on behalf of the Royal Air Force had always had its complete reward in the personal gratification of being able to be helpful in any way to the youth of the Empire-that youth which displayed such amazing courage, skill and enthusiasm in the air against the common enemy.

Dealing with the remarks of those who had taken part in the discussion, he specially welcomed Sir Charles Parsons' confirmation, based on his experience of the Farnborough enquiry, as to the valuable nature of much of the work done at the Royal Aircraft Establishment. Sir Charles's view that the future of successful commercial air transport would lie with the rigid airship was of great interest, but while he was not disposed to hold any strong views at present on the solution of a Transatlantic Air Service, he nevertheless felt that the over-all costs of running a rigid air service would be almost prohibitive, due in a large measure to the great capital outlay, and to the serious problems of terminal landing and docking facilities.

As he had explained, the Paper had been rather hurriedly prepared, and he pleaded this as an excuse for omitting to refer to the admirable work carried out by the Advisory Committee on Aeronautics. Accordingly, he was very grateful to Sir Dugald Clerk for giving a rough idea of the very varied, complex and numerous problems submitted to, and generally solved, by that important body. It was to be hoped that the problem of super- 
compression and other methods of obtaining power at high alti- Lord Weir tudes would continue to receive unremitting encouragement and development.

Colonel Ogilvie had rightly drawn attention to the ever important question of light-weight engines and to the con tributory factor of high-grade special steels in the solution of the problem. The Author did not think that any of the Institution's Sheffield friends would contest his belief that the development of highgrade steel in the last few years had been largely due to the compelling influence of aero-engine design. He thoroughly agreed with Colonel Ogilvie in regard to the necessity of the State department responsible for aviation keeping the manufacturers and designers thoroughly posted as to the experience obtained as a result of accidents.

All were indebted to General Groves for his presentment of the psychological and human aspect of flying and his reference to the cold-blooded courage of those scientific men who had deliberately risked their lives to study the phenomena in the only practicai way. It was gratifying to find the Deputy Chief of the Air Staff so thoroughly in sympathy with the practical, commercial possibilities of the flying boat.

The notes contributed by Messrs. Short Brothers and by Messrs. The Supermarine Aviation Works, Ltd., were of interest. In this connexion Messrs. Short rightly drew attention to the enormous value of the work carried out during the war by seaplanes and flying boats, and there was no doubt that the work of these coastal patrols had very substantially contributed to the subjugation of the enemy submarine.

Lord Weir said that his main reason for not dealing in detail with the development of the seaplane had been the " unfortunate" length of his Paper, and the fact that from the aerodynamic point of view the seaplane development followed much on the lines of that of the aeroplanes. The torpedo seaplane was a striking example of the many interesting and valuable developments of war-time aircraft which would have been given an opportunity if the war had continued. 


